\title{
Social interactions in health behaviors and conditions
}

\author{
Ana Balsa \\ Universidad de Montevideo \\ Carlos Díaz \\ Universidad Católica del Uruguay
}

February $19^{\text {th }}, 2018$

\begin{abstract}
We review the economic literature of the past 20 years on peer effects in health behaviors and conditions. We find consistent evidence of peer effects across a wide range of behaviors and outcomes (alcohol, body weight, food and nutrition, physical fitness, sexual behaviors, fertility, and mental health use) and across a diverse set of identification techniques (instrumental variables, network analysis, reduced form models, random assignment of peers, and discrete choice models of endogenous interactions). Despite the thorough evidence on the existence of peer effects, we still know little about the underlying mechanisms. Understanding these mechanisms is critical for the design of effective policies and constitutes the new stage in the research agenda.
\end{abstract}

\section{Keywords}

Peer effects, social interactions, peer influence, health behaviors, health conditions, systematic review, substance use, obesity, sexual behavior, mental health 


\section{Summary}

This chapter reviews the economics literature on social interactions in health behaviors. A large body of papers discuss the estimation challenges behind social interactions and the different approaches devised by economists to confront them. There are also quite a few systematic reviews on the empirical estimation of peer effects in academic and labor market outcomes. To our knowledge, this is the first systematic review in economics to cover broadly the literature on peer influence in health behaviors and conditions. We begin by raising the main methodological challenges inherent in the estimation of peer effects and relating them to the literature in health behaviors. We describe how the literature has attempted to resolve the reflection problem (simultaneity in influences) by using peers' background characteristics as instrumental variables, exploiting network structure, using lagged measures of peer behavior, comparing differences in variance across aggregate and individual behaviors, and estimating structurally discrete choice models that solve for strategic equilibria. We also illustrate how researchers have responded to the problem of homophily and common shocks through the use of neighborhood, school, family, or individual fixed effects and through the estimation of correlated random effects in structural models.

While no single technique has solved for all the challenges involved in the estimation of peer effects, our review reveals strong and robust peer effects in alcohol use, body weight, food intake, body fitness, teen pregnancy and sexual behaviors, across a wide set of populations, reference groups, and methodologies. The evidence is mixed, however, on the influence of peers on smoking, illicit drug use, and mental health.

We discuss theoretical insights and evidence on the mechanisms behind peer effects in health behaviors and their policy implications An incipient group of studies underscores an effect of social norms behind peer effects in obesity, substance use, and 
teen pregnancy. Social learning has been suggested as a channel in some studies of peer effects in fertility, mental health utilization, and medication take-up. We also discuss new developments in the study of social networks which are shedding new light on the dynamics of social influence. We conclude by highlighting the importance of understanding the mechanisms behind peer influence in order to device better policy. 


\section{Introduction}

Health behaviors are actions that affect health conditions by increasing or decreasing the odds of morbidity and mortality. Categories of health behaviors include diet, nutrition, and physical activity, tobacco, alcohol, and illicit drug use, sexual behavior, stress management, sleep patterns, health care use, and adherence to prescribed medication, among others. These behaviors may lead to health conditions such as obesity, diabetes, substance dependence, or depression. Some of these categories are more social in nature and as such, are more likely to be subject to the influence of others through social interactions. Sacerdote (2011) defines peer influence as nearly any externality that spills over from peers' backgrounds, current actions or outcomes to an individual's actions or outcomes. Market-based or price-based effects are excluded from this definition. For example, if demand for healthier food in the neighborhood increases the price of fruits and vegetables, and this increase negatively affects the intake of healthy food by an individual in that neighborhood, such an effect would not be considered a peer effect. Sacerdote's definition of peer effects allows for physiological externalities, such as the effect of smoking by an individual on a third party's health. In this article, we refer to social interactions as any type of externality in which the actions or outcomes of a reference group affect the decision process of an individual, either through changes in preferences, beliefs, or constraints. Throughout this paper, we refer intermittently to theses externalities as peer effects, peer influence or social spillovers.

Direct social interactions or externalities in preferences occur when the actions of others shape the individual's preferences, either because consumption decisions by one or more members of the reference group changes the payoff of others (payoff interactions or contagious effects), or because individuals do not wish to deviate from 
the social norm imposed by a reference group's behavior, perhaps due to fear of social sanctions (Hirshleifer 1995). Externalities in expectations or beliefs occur when individuals look at behaviors among others in a reference group to guide them on the costs and benefits of different choices (Banerjee 1992, Bikhchandani et al 1992). Finally, externalities in constraints may occur when fixed costs are high and supply does not take place until there is a critical mass of consumers. For example, healthy food stores may not open in a city until there is a minimum critical mass willing to purchase that kind of food. Constraint externalities may also be a consequence of insufficient supply of shared resources, such as gyms (Cawley et al 2017). In the presence of social spillovers, the first order condition of the consumer's maximization problem will show strategic complementarities in actions if the marginal utility to one person of undertaking an action is increasing in the average amount of the action taken by his peers (Glaeser and Scheinkeman 2001). If marginal utility is decreasing in others' actions, actions are strategic substitutes.

One of the main reasons why economists study peer effects is that social interactions impose externalities on others that lead to inefficient market outcomes, justifying market intervention. In the presence of strategic complementarities in behaviors, social interactions will multiply the effects of policies and programs. The strength of this multiplier will depend on the strength of peer influence. The study of social interactions in economics has expanded in the past years also from the need to better understand the motivations and intentions behind individual behavior, in particular under the impulse of behavioral economics and network analysis.

This chapter reviews the economics literature on social interactions in health behaviors. A large body of papers discusses the estimation challenges behind social interactions and the different approaches devised by economists to confront them. There 
are also quite a few systematic reviews on the empirical estimation of peer effects in academic and labor market outcomes. To our knowledge, this is the first systematic review in economics covering broadly the literature on peer influence in health behaviors and conditions.

Following the network literature, throughout the chapter we refer sometimes to the individual whose behavior may be affected as the ego, and to the individual or individuals (peers) who may be affecting the ego as the alter.

In Section 2 we raise the main methodological challenges inherent in the estimation of peer effects and relate them to the literature in health behaviors. We describe how the literature has attempted to address the reflection problem (simultaneity in influences) by using peers' background characteristics as instrumental variables, exploiting network structure, using lagged measures of peer behavior, comparing differences in variance across aggregate and individual behaviors, estimating structurally discrete choice models that solve for strategic equilibria, and estimation partial population models. We also illustrate how researchers have responded to the problem of homophily and common shocks through the use of neighborhood, school, family, or individual fixed effects and through the estimation of correlated random effects in structural models.

Section 3 reports the main findings of the literature on peer effects in health behaviors and conditions for the past two decades. The empirical evidence shows strong and robust peer effects in alcohol use, body weight, food intake, body fitness, teen pregnancy and sexual behaviors. The evidence is mixed, however, on peer effects in smoking, illicit drug use, and mental health.

We discuss theoretical insights and evidence on the mechanisms behind peer effects in health behaviors and their policy implications in section 4 . The yet incipient evidence underscores an effect of social norms or social conformism behind peer effects in 
obesity, substance use, and teen pregnancy. Social learning has also been pointed as a channel in some studies of peer effects in fertility, mental health utilization, and uptake of medication. In this section we also discuss new developments in the study of social networks which are shedding new light on the dynamics of social influence.

We conclude in Section 5 by highlighting the importance of better understanding the mechanisms behind peer influence in health behavior in order to device better policies.

\section{Methodological issues in the estimation of peer effects}

\subsection{The challenges of estimating peer effects}

In a seminal paper, Manski (1993) identified three distinct types of correlations in outcomes or behaviors that result from social interactions: (i) correlated effects, (ii) contextual effects, and (iii) endogenous effects. Correlated effects are statistical associations between individuals' behaviors that occur either because individuals tend to form ties to similar others (selection or homophily) or because they share the same environments with others. The other two categories involve particular cases of social influence. Contextual effects occur when the propensity of an individual to behave in certain way varies with the distribution of background characteristics in the group (Manski 1993). Endogenous effects, in contrast, occur when the behavior of a peer or a group of peers directly influences the behavior of the individual. A key to endogenous effects is the simultaneity between the individual's and peers' choices.

While both contextual and endogenous effects are types of social interactions, they have very different policy implications. When endogenous effects are present, a policy such as a sin tax can have multiplier effects: the policy will impact the individual both directly and indirectly through the influence on his/her peers. If peer effects are just contextual, policy will not have multiplying effects. Contextual effects can only be 
exploited policy-wise by changing the composition of the group the individual belongs to and/or by focusing policy efforts on individuals strategically positioned in the social network.

Contextual effects are not easily distinguishable empirically from endogenous effects. A group of schoolmates may have unhealthy eating habits because their parents have preferences towards unhealthy food and the habits in these families spill over to the students in the same grade. If students' food choices depend strongly on family habits and these habits are not easily observed by the econometrician, social interactions in food choices may be taken as endogenous when they are just contextual. In such case, a school policy that makes unhealthy food unavailable at school will mistakenly be assumed to have multiplier effects when it will not. Furthermore, even when knowing that the effects are contextual, we may not be focusing on the specific underlying trigger. In the example above, unhealthy eating habits may be correlated with peers' family education, while it is family food preferences (correlated with family education) what really matters.

The main challenge in the estimation of endogenous effects stems from the simultaneity of influences between an individual's behavior and that of the peer group. In the presence of endogenous social interactions, an individual's behavior will reflect the behavior of the group, and the groups' behavior will reflect that of the individual. This reflection problem, as defined by Manski (1993), is critical when the estimated effects are linear-in-means, that is, when the behavior of interest is influenced by the average behavior of the peer group. This is because the reflection problem relies strictly in perfect collinearity between an individual's behavior and his/her peers' average behavior. The problem is less critical in non-linear settings, although multicollinearity 
may still be an important issue in these cases, and estimated parameters may be imprecise.

Additional challenges in the estimation of peer effects include measurement error and specification error. One main source of measurement error arises from the difficulty in defining the relevant peer group. Compared to neighborhoods, schools have geographic and social boundaries of interaction that are more precise. However, students do not interact with everyone at school. The assumption that each neighbor or each student in a school, a grade or a class is a relevant influencer may introduce measurement error in the estimation (Ludwig et al 2008). This problem is enhanced by the fact that researchers are unlikely to have a full sample of all individuals that exert an influence on an ego. Using sampled students' means or regional means in a regression is problematic because the sample means will be measured with sampling error, which attenuates estimates on the regional or school-level aggregates (Miclewright et al 2012).

Measurement error may also stem from reporting errors in peer behaviors. While the issue is less critical when estimating peer effects on test scores, it is nontrivial when studying health behaviors, which are usually measured on the basis of self-reports from survey data. Misreporting may result from inaccuracies arising from comprehension, recall, and other cognitive operations or from factors related to the social desirability of the behavior and the interviewing conditions (Brener et al 2003).

For some behaviors and populations, self-reports have shown small degrees of inaccuracies. For example, the validity of self-reported smoking is consistently high in population-based studies that compare self-reported data to biological markers of cotinine levels (Wagenknecht et al 1992, Vartiainen et al 2002, Rebagliato 2002). However, smoking status is more likely to be underreported by populations in smokingcessation programs (Boyd et al 1998) or by teenagers (Patrick et al 1994, Rebagliato 
2002). Edoka (2017) shows that smoking misreporting among adolescents results in a downwards bias of marginal effect estimates of tobacco use. In the case of alcohol use, the evidence also points towards a high reliability of general population self-reports (Polich 1982, Glovannucci 1991). But, heavy drinkers are more likely to underestimate drinking behavior (Townshend and Duka 2002). Similarly, there is evidence that obese individuals, female endurance athletes and adolescents tend to understate their weight and food intake and to misreport weight control behaviors (Schoeller 1995, Nawaz and Katz 2001, Huybrechts et al, 2006, Cawley and Burkhauser 2006, Burkhauser and Cawley 2008, Shields et al 2011).

The above evidence suggests that misreport tends to be higher among individuals more likely to incur in unhealthy behaviors such as substance use, intake of unhealthy food, or adoption of unhealthy weight control methods. This negative covariance between the true explanatory variable of interest and measurement error does not have the classical errors in means specification. Most likely, it resembles the mean reverting measurement error found by Bound and Krueger (1991) in earnings data. In such case, attenuation bias will decrease (relative to the case of classical measurement error) whenever the variance in measurement error is small relative to the variance in the underlying true variable. But it will increase, even to the point of reverting the sign of the coefficient, whenever the variance in measurement error is large relative to the variance of the underlying true variable. The problem introduced by measurement error is further complicated by the fact that the dependent variable in peer effects models is also likely to show a negative correlation between the underlying true variable and measurement error.

Finally, misspecification error can also bias the estimates if model assumptions do not hold. These include assumptions about the choice of covariates, the interactions 
between social variables and individual decisions, or assumption derived from theory and functional form specifications.

\subsection{Empirical approaches in the estimation of peer effects in health}

\section{behaviors and conditions}

The typical social-interactions-specification assumes that an individual's action (health behavior or condition) depends linearly on personal characteristics, environmental characteristics, peers' choices regarding that same health behavior, and (in some models) on peers' background characteristics. Once a reference group is defined, most empirical models of peer influence in health behaviors assume that the association between peers' actions and the individual's action is linear in means.

\subsubsection{Addressing the reflection problem}

When the model is linear-in-means, the estimate of a coefficient of ego's behavior on average-peer-behavior will be inconsistent due to the reflection problem. Approaches aimed at resolving reflection include the use of peers' background characteristics as instrumental variables, exploiting the incomplete structure of the network, using lagged rather than contemporaneous measures of peer behavior, exploiting differences in the variance of behaviors at the aggregate-versus individual-level, estimating structurally discrete choice models that solve for strategic equilibria, or running partial population models.

a) Identification using instrumental variables: peers' family background, exogenous shocks and genetic phenotypes

The most circulated avenue in reduced form studies to get past the reflection problem has been to use instrumental variables. This approach replaces peers' average behavior for some residual variation in peers' behavior that is uncorrelated with ego's choices. Adequate instruments need to be sufficiently correlated with peers' average 
behavior, but excludable from the individual equation; the only channel through which they can influence the individual's behavior is through the peers' behavior.

Most studies dealing with peer effects in school settings have used peers' average family-background characteristics to instrument for peers' average behavior. Two assumptions must be satisfied for these variables to be good instruments. The first one is that contextual effects are non-existent, i.e. that peers' parents and siblings do not directly affect the individual's behaviors. Second, the model must adequately control for environmental characteristics that could be associated with peers' background profile due to endogenous sorting. In papers dealing with substance use, the set of family background instruments has included peers' parents' socio-demographics (parents' marital status, race, nationality, education), peers' family structure, peers' parents' involvement with their children, availability of substances at peers' households, and use of substances by peers' parents and siblings (Gaviria and Raphael 2001, Powell et al 2005, Lundborg 2006, Sen 2009, Fletcher 2010, Ali et al 2011, Halliday and Kwak 2012, Fletcher 2012, McVicar and Polanski 2014, Gwozdz et al 2015). Studies analyzing peer effects in weight and obesity have used the BMI or obesity status of the peers' parents to instrument for peer obesity in school settings (Trogdon et al 2008, Renna et al 2008) or regional means of sociodemographic characteristics to instrument for regional prevalence of obesity (Auld 2011). Peers' mothers' teen childbearing, mother and fathers' college education and peers' average age of menarche have been used to instrument for peers' likelihood of having a teen pregnancy.

The main problem with peer-family-background instruments is that they rely on the assumption of no contextual effects. The excludability of these instruments is questionable if peers' family characteristics or regional features have a direct impact on the individual's behavior (i.e. if contextual effects are different from zero), aside from 
the influence through the peer's behavior. In fact, it is not hard to think of situations in which a student's behavior regarding the use of substances is affected directly by the availability of alcohol at friends' homes, by friends' older siblings, or by the parents of their friends, through conversations and example. Furthermore, friendships selection may be associated to friends' use of substances or weight status. If tendencies towards substance abuse or obesity are heritable, because of selection and heritability, an obese youth will be more likely to be surrounded by obese parents of peers. Finally, some of these instruments may violate the monotonicity condition required for the estimation of local average treatment effects. Monotonicity requires that the instruments shift the behavior of all individuals in the same way. For example, we would expect an individual who drinks when alcohol is not easily available at home to drink also when alcohol is available. Such assumption may not hold if the offspring of a heavy drinker reacts to parental substance abuse by being abstinent. In the presence of defiers, the instrumental variables estimates do not represent local average treatment effects. ${ }^{1}$

Other instrumental variables studies have used variation stemming from policy or other type of shocks that affects peers but do not affect the ego. In an analysis of spouses' influence in smoking behavior, Cutler and Glaeser (2010) use smoking bans in the spouse's workplace to instrument for the spouse's smoking. Monstad et al (2011) instrument a sibling's teen pregnancy using variation in exposure to an educational reform that increased the minimum school leaving age in Norway. Yakusheva and Fletcher (2015) use a close friend's miscarriage as an exogenous shock to the friend's likelihood of giving birth.

\footnotetext{
${ }^{1}$ Some have argued that using peers' family malleable characteristics as instruments may even suffer from a "second-order case of the reflection problem: friend's parents' weight may be affected by friend's weight which in turn may be affected by the respondent's weight" (Cawley and Ruhm, 2011, p. 49).
} 
Finally, a very recent set of studies uses peers' genetic information to address the reflection problem. Sotoudeh et al (2017) use peers' distribution of polygenic scores associated with tobacco use to instrument for peer smoking. A polygenic score is a weighted average or composite score that takes into account information across an individual's entire genome to measure his/her genetic predisposition or risk for a particular outcome. The authors argue that polygenic scores are good candidates for breaking the reflection problem because they are determined prior to birth and correlate with health behaviors. When running the instrumental variables regression, the authors control for a wide set of individual and peer average characteristics, including the ego's own polygenic score and peers' parents' and siblings' average smoking, to dismiss the effect of direct contextual influence from the peers' families. Cawley et al (2017) criticize the use of genes as instrumental variables. While they agree that genes contribute to address the reflection problem, using them as instruments requires the assumption that they are excludable from the individual smoking equation, that is, that they only affect the individual's smoking through peers' smoking. But peers' genetic predisposition could trigger, for example, reactions by classroom teachers, who may devise strategies for students in that classroom to reduce their smoking. Or, genetic predisposition may be correlated with other traits, such as discount rates, which may affect smoking through other channels (higher likelihood of being idle, using alcohol, and so forth).

Aside from the reflection problem, instrumental variables may contribute to address the problem of measurement error whenever the peer effects variable is measured with error and the instruments are uncorrelated with the measured error. Because measurement error results in attenuation bias, we expect the estimates to be higher when using instrumental variables estimation. On the other hand, and conditional on having 
strong and valid instruments, we expect instrumental variables estimates to be smaller than naïve estimates when addressing the reflection problem (if actions are strategic complements). The sign and magnitude of the difference between instrumental variables estimates and naïve parameters will thus be an empirical matter.

A final and non-trivial issue with instrumental variables in general is that instruments may be weak after using fixed effects approaches that account for selection. Halliday and Kwak (2012) show that many of the family background instruments used by prior researchers show little variability once school fixed effects have been accounted for. Estimates will be biased in the presence of weak instruments.

\section{b) Identification using network structure}

A more recent and growing source of identification comes from the structure of social networks (Bramoullé et al 2009). The social network approach exploits the fact that not everyone interacts with everyone in a social group (i.e., networks are usually not complete). In network analysis, a peer group includes only those individuals that have connections with the ego. The social intransitivity in relationships that results from network incompleteness breaks the reflection problem, as the background characteristics of friends of friends, but not friends of ego, can be used to instrument for friends' behavior. Studies using this identification strategy have used friends of peers' parental marital status, parental educational attainment, presence or number of older sibling(s), family structure, alcohol availability at home, and financial, socio-cultural, and physical environment characteristics, among others, to instrument for peers' substance use, body weight, sport activities or food consumption (Ajilore et al 2016, Moriarty et al 2016, Mora and Gil 2013, Leonard et al 2014, Liu et al 2014, Fortin and Yazbeck 2015). Unlike prior literature, the social network approach gets around the reflection problem without having to assume the absence of contextual effects. It 
focuses, in addition, on peer groups that are arguably more relevant than those defined by analytical convenience (such as school peers, randomly assigned college roommates or neighbors). However, the network approach has not been able to resolve the problem of the endogenous formation of network links, an issue we come to in the following section.

The strength of identification in network analysis is likely to depend on the density of the network. As with other instrumental variables models, the instruments may end up being weak after using network fixed effects to account for network-related correlated effects.

c) Reduced form models that combine contextual and endogenous effects

In light of the difficulties involved in finding good instruments and in getting rid of correlated effects in network analysis, some authors have turned to running reduced form regressions of individual behavior on peers' background characteristics, controlling for individual-level characteristics. The coefficients on these peer characteristics capture social interactions, but as reduced forms of more comprehensive social interaction models, they are unable to distinguish between endogenous and exogenous influences (Manski 1993). Authors that have pursued this avenue in the substance use literature include Argys and Rees (2008), who study the effect of peers' age on ego's alcohol use, and Bifulco et al (2011), who explore the impact of peers' maternal education and fraction of school-year peers who are minorities on ego's probability of smoking, binge drinking, and using marijuana. Black et al (2013) analyze the impact of gender and family education on teenage pregnancy. Cawley et al (2017) run reduced form models of an individual's weight and obesity on the genetic predisposition of his/her siblings' towards having high body mass index (BMI). As argued by the authors, the use of genetic risk scores as instrumental variables would 
need to assume that the only channel through which the siblings' genes can affect the individual's BMI is through the sibling's own BMI (in other words, it would need to assume that siblings' genes have no contextual effects on the individual). Siblings' genes, however, could affect the food that is prepared at home, the promotion of exercise in the household, or other traits of the individual different from BMI, and could thus have an influence on the individual's BMI through other channels. Sotoudeh et al (2017) take this argument further and question the adequacy of using siblings' genes to explain social interactions at the family level. Because siblings' genes will be correlated with parental genes, they may be a proxy for environmental common shocks that result from parents' behavior (food or fitness related) and that influence siblings' weight. If the direction comes from parents' genes' to both children's outcomes rather than from siblings' genes to ego's outcome it would not be a sibling-generated contextual effect.

While statistically simpler, the approaches regressing ego's behavior on peers' background characteristics are unable to generate well-defined policy recommendations, as it is not clear whether these effects convey social multipliers that would enhance the impacts of policies or programs. Furthermore, reduced form approaches cannot assert whether it is the explanatory variable of interest per se (parents' education, siblings' genes, classmates' gender or racial background) the source of social influence, or if it is just a proxy for other unobservable triggers.

Some authors have suggested using perceptions of peer behavior, rather than measures of peer behavior, as a means for resolving the reflection problem (Kawaguchi 2004). Norton et al (2003) raise three reasons why such an approach leads to inconsistent estimates. First, individuals perceive their own behavioral choices as relatively common and alternative choices as relatively uncommon (false consensus effect), thereby projecting their own behavior onto the groups' in subjective 
assessments. Second, there is evidence that certain populations, such as adolescents, tend to overestimate the prevalence of substance use, regardless of their own behavior (scaling effect). Finally, subjective estimates of peer health behaviors may incorporate simple random error (measurement error effect).

\section{d) Identification using lagged measures of peer use}

An alternative road around the reflection problem has been to replace contemporary measures of peer behavior with measures that pre-date the appearance of a social link. This has been the usual approach in studies exploiting random assignment of college students (Duncan et al 2005, Eisenberg et al 2014, Yakusheva et al 2011, 2014). Since current choices by the individual cannot impact past peer choices, the use of past peer behavior addresses simultaneity. Some authors have used peer past behavior as the main explanatory variable in settings in which links were formed prior to collecting the data (Clark and Lohéac 2007, Balsa et al 2018). These studies may not get rid of simultaneity if current use by the ego (the dependent variable) is correlated with peers' lagged use (the explanatory variable) through the ego's own lagged use. One way to avoid this problem is to condition the regression on the ego's past behavior. Still, the model would rely on certain assumptions about the lag structure of social influence and would run the risk of misspecification (Manski 2005). Furthermore, lagged peer outcomes may overlook recent changes in peer behavior, which might influence an individual's outcomes. They are therefore at best interpretable as lower bounds estimates of the peer effect of interest (Hanushek et al 2003).

e) Identification using equilibrium discrete choice models (structural estimation)

Structural models respond to the problem of reflection by endogenously modelling individual and peers' choices and focusing on the equilibrium outcomes (Brock and Durlauf 2001a). In discrete-choice models with endogenous social interactions, an ego's 
net utility from an action depends on the observed or expected actions of other individuals. The model's equilibria incorporate the feedback that each choice generates on the whole network and these equilibria define the conditional likelihood functions used to estimate the social interaction parameters.

Many of the discrete choice structural studies of peer effects in health behaviors analyze interactions in small groups, and assume that individuals can fully observe the choices of others. ${ }^{2}$ In these models, individual payoffs depend on the actual choices of all others in the group (Krauth 2006, 2007, Clark and Etilé 2006, Nakajima 2007, Soetevent and Kooreman 2007, Harris and González López-Valcárcel 2008, Card and Giuliano 2013). Because the non-cooperative Nash equilibria of these models may generate multiple equilibria, it requires the choice of an equilibrium selection rule for estimation. The fundamental identification problem of these structural models relies on selecting the right equilibrium and on finding variation in the data that shifts an individual's choice without shifting that of his/her peers.

Clark and Etilé (2006) estimate a structural game of peer effects in smoking across spouses. The authors consider a two-player non-cooperative binary game in which each individual's smoking decision depends on own smoking and on the spouse's past smoking. For certain combinations of private payoffs, the model allows for multiple equilibria, in which case a mixed-strategy equilibrium defines the appropriate threatpoints. The model is estimated assuming a bivariate probit model. Nakajima (2007) assumes that youth smoking decisions occur sequentially rather than simultaneously. Peer interactions occur frequently and are reciprocal across students of the same school

\footnotetext{
${ }^{2}$ This is unlike the original discrete choice model proposed by Brock and Durlauf (2001), who assumed that individuals interact in large groups, have incomplete information about others' actions and form rational expectations about others' behaviors (approximated by the population average of the observed choices).
} 
and cohort, making all outcomes endogenous. The author bases the model on a Markov dynamic interaction process, in which students respond to the observed smoking or nonsmoking actions of others without trying to anticipate their actions in the future. This process converges to a steady state distribution of the interaction process, which is used to construct the likelihood function for estimation. Identification is achieved through the parameterization of the utility function and by assuming interactions are uniform across individuals of similar types (gender, race). Soetevent and Kooreman (2007) also consider a discrete choice model with a small number of players and apply it to a range of self-reported behaviors (including smoking) among Dutch adolescent students. The authors provide upper bounds on the number of equilibria that occur if interactions are strategic complements rather than strategic substitutes, which depend on the interaction strength and the number of agents. For identification, they assume that contextual effects are non-existent. Harris and González López-Valcárcel (2008) explore asymmetric social influences in smoking behavior between siblings by considering a multi-player non-cooperative binary game similar to the two-player game studied by Clark and Etilé (2006). The model allows for differential influence of smoking and nonsmoking siblings. To avoid the indeterminacy due to multiple equilibria, they rely on a sequential-move solution, in which older players move first. Card and Giuliano (2013) model the behavioral choices (regarding sexual behavior, smoking, and marijuana initiation) of self-nominated friends' pairs at school, allowing for social interaction effects as well as for correlated unobservable determinants of their joint behavior. They identify individual behavior from peers' behavior by using individual traits, such as physical development, correlated with own behavior but not with that of the friends. Finally, Lin (2014) assumes that agents do not have complete information on peers' behaviors. The author estimates a discrete choice model in which agents interact only 
with a subset of the group, have partial information on peers' choices, and form rational expectations about heterogeneous peers. Such model generates a unique equilibrium for a wide range of parameters.

While structural models have the advantage of embedding theoretical insights into the estimation, they also face a higher risk of misspecification. Identification usually relies on assumptions about functional forms, parameter distributions, and equilibrium selection rules, which are strong and not necessarily testable. Krauth (2005) shows that the bias due to an incorrectly specified equilibrium selection rule increases gradually in the strength of the peer effect. Furthermore, the computational cost and complexity of structural estimators is far greater than that of OLS or IV methods. As with much of the reduced form literature, endogenous effects in many of these models are identified under the assumption that there are no contextual effects.

\section{f) Individual vs. aggregate level variation}

Glaeser and Scheinkman (2001) and Glaeser et al (2003) propose a different way of identifying social multipliers. Their approach consists of inferring the presence of social interactions from contrasts between regression coefficients at the individual and aggregate levels, as well as from comparisons between observed variance across regions and the variance we would expect to observe from sampling noise if people were randomly distributed across regions and there were no social interactions whatsoever. This technique is utilized by Auld (2011), who studies regional peer effects on BMI and obesity, and by Cutler and Glaeser (2010), who explore the effects of smoking by peers of the same age, gender and living in the same metropolitan area as ego on ego's smoking participation. The main problem with this methodology is that aggregate and individual effects must be residualized from environmental correlates before being 
contrasted. This residualization usually relies on observable correlates but cannot get rid of correlated effects that are unobservable.

\section{g) Partial population models}

Partial population designs (Moffit 2001) originate from a sample of social groups between which there are no spillovers. Some of these groups are randomly designated for treatment, and within these, a random subset of agents is treated. The difference between the mean outcomes of untreated subjects in treatment and control groups captures the spillovers effect of group treatment on untreated subjects. Miguel and Kremer (2007) use this approach to assess spillovers in take-up of deworming medication in Kenya. Babcock and Hartman (2010) employ it to study the spillovers of a treatment aimed at incentivizing gym attendance.

\subsubsection{Addressing correlated effects}

Distinguishing true peer effects from correlated effects due to selection or homophily is not an easy task. The most credible approaches rely on the random or quasi random assignment of individuals to groups of peers. Studies using random assignment have analyzed social influences in health behaviors among individuals randomly assigned to roommates in college (Duncan et al 2005, Yakusheva et al 2011, 2014, Eisenberg et al 2014), to squadrons in the air force (Carrell et al 2011) or to neighborhoods (Ludwig et al 2011).

Other studies have exploited the quasi-random assignment of students across cohorts in schools, defining the peer group at the school-grade level (Clark and Lohéac 2007, Trogdon et al 2008, Sen 2009, Fletcher 2010, Ali et al 2011, Bifulco et al 2011, Halliday and Kwak 2012, Fletcher 2012, Ajilore et al 2016, Moriarty et al 2016, Sotoudeh et al 2017), or across classes within a school-grade if classes are randomly assigned within grades-in which case the peer group is defined at the class level- 
(Lundborg et al 2006, Lim and Meer 2018, Balsa et al 2018). These studies rely on parents' ability to choose the school but not the cohort or class where their children will be placed in. In such settings, the use of school or school-year fixed effects captures time invariant unobserved features of the school correlated with parental preferences. Some studies with longitudinal data have also addressed unobserved heterogeneity by using individual fixed effects (Sen 2009, Cohen Cole and Fletcher 2008, Halliday and Kwak 2009, Gwozdz et al 2015, Moriarty et al 2016), although attenuation bias constitutes a non-trivial threat in settings with large number of individuals and few time periods (Deaton 1995).

Studies based on random or quasi-random variation rely on peer groups that are opportunistic to the analyst, but that do not necessarily reflect the natural channels of influence. The influence that results from experimentally assigned groups may be quite different from that exerted in groups of peers that have formed by choice. Several studies have compared estimates from analyses defining the peers at the school-cohort level with estimates identifying peers from self-nominated friends (Clark and Lohéac 2007, Ali et al 2011, Halliday and Kwak 2012, McVicar and Polanski 2014). Some of these authors interpret the higher magnitude and strength of estimates based on nominated friends as evidence of the stronger influence of close group of friends. Such comparisons, however, fail to account for the fact that links within networks are endogenous, and that the estimates based on nominated friends may suffer from selection bias.

Most analyses of peer influence in health behaviors using social networks adjust for school fixed effects or for network fixed effects. The assumption for identification is that, once the network has formed, within-network link formation takes place randomly or based on observable individual characteristics only. However, link formation 
decisions may be given endogenously by unobservable characteristics that are also correlated with health behaviors (Fortin and Yazbec 2015).

In structural models, correlated effects have been taken care of through the inclusion of county, school, family or individual fixed effects and through the estimation of correlated random effects. Clark and Etilé (2006) exploit the variation in spouses' smoking behavior over nine waves of data and allow for correlation between spouses' individual constant traits and between their unobserved time-varying error terms. Nakajima (2007) controls for county-fixed effects to address unobserved heterogeneity at the county level, while Soetevent and Kooreman (2007) use school fixed effects to account for non-random selection into schools, and allow for within class correlation of error terms to account for common shocks. In Krauth $(2006,2007)$ selection and common shocks are addressed by imposing the assumption that the correlation in unobservable variables equals the correlation in observable variables. Harris and González López-Valcárcel (2008) assume a specific random-effects error structure to address the problem of common shocks. Card and Giuliano (2013) estimate correlated random effects across friends' behavioral equations. A current line of research in structural models of peer effects has been trying to embed the mechanisms by which groups are formed into their models. Efforts in this sense are beginning to appear but are still incipient in the literature (Hsieh and Lee 2016).

\section{Evidence of peer effects in health behaviors}

\subsection{Peer effects in substance use}

Table 1 depicts the most relevant papers that have studied peer interactions in substance use in the past 20 years. In what follows, we present separate evidence for tobacco, alcohol, and illicit drug use.

\subsubsection{Peer effects in tobacco use}


Most analyses of peer influence in tobacco use aim at estimating the effects of peers' tobacco prevalence on the individual's likelihood of having smoked in the past 30 days. Estimates go from 0 to 0.6 , implying that, in the upper range, a 10 percentage point increase in peers' prevalence of smoking increases the ego's likelihood of smoking by 6 percentage points. Most studies using instrumental variables estimation (e.g., peer family background characteristics, peer genotype) in school samples tend to find statistically significant and relatively large effects (Gaviria and Raphael 2001, Powell et al 2005, Lundborg 2006, Fletcher 2010, McVicar and Polanski 2014, Sotoudeh et al 2017). Most of these studies use school fixed effects to control for unobserved heterogeneity. Outside of the school setting, Cutler and Glaeser (2010) estimate an effect of 0.40 when using workplace smoking bans to instrument for a spouse's smoking choice.

Beyond IV approaches, Clark and Lohéac (2007) regress current individual smoking on male peers' lagged smoking prevalence, school fixed effects and other covariates. They find an estimate for peer influence in smoking of 0.088 . Also in a school setting in Canada, Sen (2009) finds that smoking by same gender peers has an effect on female ego's smoking of 0.298 and of 0.387 for male ego's smoking. The approach uses individual fixed effects to control for unobserved heterogeneity.

In terms of reduced form models that regress ego's use on peers' background characteristics, Argys and Rees (2008) show that for females (but not for males), being younger than the average student in the cohort increases the likelihood of smoking by 0.041 percentage points. Bifulco et al (2011) do not find evidence of a correlation between the fraction of peers with college educated mothers or the fraction of minorities in the school-year and ego's smoking, after controlling for school fixed effects and other covariates. 
Unlike IV and other reduced form studies, the only study relying on randomly assigned college roommates (Eisenberg et al 2014) -the cleanest approach to dismiss correlated effects- does not find statistically significant effects of past roommate's smoking prevalence on the ego's current use of tobacco. Neither do most structural models after addressing unobserved heterogeneity (Krauth 2006, Clark and Etilé 2006, Card and Giuliano 2013, and Soestevent and Kooremenan 2007). One exception is Harris and González López-Valcárcel (2008), who study asymmetric social interactions in a household environment. They find that an additional smoking sibling in the household increases the likelihood that ego smokes by 0.479 , whereas an additional non/smoking sibling decreases his/her likelihood by 0.329 . Nakajima (2007) also finds a coefficient of 0.12 on peer smoking when estimating a random utility model.

\subsubsection{Peer effects in alcohol use}

Unlike the mixed case of tobacco, most empirical evidence points to positive and statistically significant peer interactions in alcohol use. Among studies using random assignment of college roommates, Duncan et al (2005) find that, for male students that binge drank in high school, having a roommate who also binge drank in the past increases the frequency of binge drinking in college by 3.83 times per month (almost doubling the average frequency). No robust roommate effects are encountered for females. Eisenberg et al (2014) estimate that being assigned a college roommate who binge drank before entering college increases the probability that the student binge drinks by 8.6 percentage points, even after conditioning on peers' contextual characteristics.

As noted for the tobacco literature, papers that use peers' family background characteristics to instrument for peer behavior (Case and Katz 1991, Gaviria and Raphael 2001, Lundborg 2006, Fletecher 2012, McVicar and Polanski 2014) usually 
produce higher estimates of peer effects (from 0.2 to 0.7 ). Effects are quite large even in studies using friend of friends' family background characteristics as instruments for peer behavior (Ajilore and Amialchuk 2016).

Studies using reduced form approaches also find evidence of positive peer effects in alcohol use. Clark and Lohéac (2007) find that a 10 percentage point increase in peers' past prevalence, increases ego's alcohol use by 1.8 percentage points, after controlling for school fixed effects and other covariates. Results in Argys and Rees (2008) show that, for females, being younger than the average student in a cohort increases the likelihood of using alcohol among US teenagers by 3.5 percentage points. Findings from Balsa et al (2014) reveal that a student's relative socioeconomic status in the school-year (relative deprivation) is positively associated with alcohol consumption and drinking to intoxication for adolescent males, but not for females. Bifulco et al (2011), on the other hand, do not find evidence of social interactions when regressing a student's likelihood of binge drinking on the fraction of peers with college educated mothers or the fraction of minorities in the school year.

Lin (2014) uses a binary choice model with social interactions under heterogenous rational expectations. Both endogenous and contextual effects are identified in their model. Correlated effects caused by commonly observed or unobserved characteristics shared by students within the same school are controlled for by school fixed effects. Using nominated friends as the relevant peer group, results show an endogenous peer effect of 0.499 for alcohol drinking.

\subsubsection{Peer effects in illicit drug use}

None of the studies exploiting random assignment of roommates in US colleges find evidence of statistically significant peer effects in illicit drug use (Duncan et al 2005, Eisenberg et al 2014). However, as with the other substances, peer estimates are 
statistically significant, and quite large, when employing IV methods that use family background characteristics to instrument for peer use (Case and Katz 1991, Gaviria and Raphael 2001, Lundborg 2006, Ali et al 2011 and McVicar and Polanski 2014). In these studies, peer effects range from 0.2 to 0.6 . Using friends of friends' family background characteristics as instruments, Moriarty et al (2016) are unable to reject the hypothesis that peer influence in marijuana use equals zero. Their estimate is positive but imprecise, probably due to weak instruments. When using individual fixed effects (rather than IVs) with longitudinal data, they find a statistically significant effect on lagged friends' prevalence of cannabis use of 0.076 .

The findings from studies using reduced form approaches deliver mixed results. Clark and Lohéac (2007) do not find evidence of peer effects in marijuana use when regressing ego's use on male and female school-year-peers' past prevalence of marijuana use. Argys and Rees (2008), on the other hand, find that females that are younger than the average student in the cohort are more likely to use marijuana. Bifulco et al (2011) find that an increase of 10 percentage points in the fraction of peers with college educated mothers decreases marijuana use by approximately 3 and 4-5 percentage points during and after high-school, respectively.

Card and Giuliano (2013) offer the only structural estimates we are aware of for peer effects in illicit drug use. They find that low intensity use of marijuana by a best friend increases ego's use by 0.45 percentage points, but they do not find high intensity use by peers to have a statistically significant influence. They however suggest precaution when interpreting this estimate, as they get an unintuitive negative correlation between the unobservables of both friends.

\subsection{Peer effects in weight and weight related behaviors}

The paper by Christakis and Fowler (2007) jumpstarted the economics literature on 
peer effects in weight and weight related behavior (see Table 2). Christakis and Fowler studied peer effects in body mass index (BMI) and obesity for men and women in the offspring cohort of Framingham Heart Study, a densely interconnected social network of 12,067 people aged 21 or older, assessed repeatedly from 1971 to 2003 . Running logistic regressions of ego's obesity on each peer's past and contemporaneous obesity, and conditioning on ego's own past obesity, the authors find that a person's chances of becoming obese increase by $57 \%$ if he or she has an obese friend (marginal effect of 0.62). They also show that effects are strongest for reciprocated friendships and nonsignificant when the friendship is perceived by the alter, but not by the ego.

Cohen Cole and Fletcher (2008) challenge Christakis and Fowler's findings by claiming that their analysis does not sufficiently account for contextual effects, and that their method of controlling for selection is "much too narrow in scope." To illustrate their claims, they replicate Christakis and Fowler's analysis using Add Health data ${ }^{3}$, and defining the alter as the friend of the respondent with the highest nomination in wave 1. They show that the peer effect becomes non-significant after the model accounts for school-specific trends and individual fixed effects. They conclude that the social correlations identified by Christakis and Fowler must be due to common environmental characteristics shared by the members of the network.

Fowler and Christakis (2008) reply by rerunning Cohen Cole and Fletcher's analysis on Add Health data with some variations: they track friendship nominations over time, use all available nominated friends rather than the first friend named, and impute missing data using expectation maximization. With these changes, they find a statistically significant effect of peers' contemporaneous BMI on ego's gain in BMI of 0.033, robust to the inclusion of school trends. They also run individual fixed effects

\footnotetext{
${ }^{3}$ Add Health is a nationally representative panel of US adolescents aged between 14 and 19 in 1994/95
} 
and find a statistically significant coefficient of 0.053 . Finally, they underscore the fact that peer effects are stronger when the alter is the named friend, and non-significant when the alter is the person who named the friend.

Other studies have also used Add Health data to estimate peer effects in weight and weight related behaviors. Halliday and Kwak's (2009) findings on peer effects in BMI and overweight lose statistical significance when individual fixed effects are included. Trogdon et al (2008) and Renna et al (2008) use friends' background characteristics to instrument for close friends' $\mathrm{BMI}^{4}$ and include school fixed effects to account for unobserved heterogeneity at the school level. Trogdon et al (2008) estimate an IV coefficient of $0.52^{5}$, while Renna et al (2008) find an IV coefficient of 0.252 for females, and an imprecise coefficient for males.

Loh and Li (2013), Gwozdz et al (2015) and Lim and Meer (2018) also use peers' parental characteristics to instrument for peers' average BMI. In Loh and Li (2013), the relevant peer group is children in the same age range and school, and residing in the same community in rural China. The authors find an IV estimate for the full sample of $0.273 .{ }^{6}$ Gwozdz et al (2015) study peer effects among children aged 2 to 9 in eight European countries. Findings reveal a peer effect of $0.368 .^{7}$ Both the analyses in Loh and $\mathrm{Li}$ (2013) and Gwozdz et al (2015) are limited by the fact that they use only observable community characteristics to control for correlated effects. Lim and Meer

\footnotetext{
${ }^{4}$ The instruments used by Trogdon et al (2008) are friends' parents' obesity and health, and friends' birth weight while Renna et al (2008) use friends' parents' obesity.

${ }^{5}$ Trogdon et al (2008) also analyze overweight and find that a 10 percentage point increase in peers' prevalence of overweight increases ego's overweight by 3.9 percentage point in the full sample and by 5.3 percentage point in the case of female subjects.

${ }^{6}$ Their set of instruments include peers' parents' BMI and the fraction of peers' parents born during the Great Famine.

${ }^{7}$ Peer effects show substantial variation among the regions, with generally larger effects in the Spanish, Italian, and Cypriot regions than in the German, Swedish, Belgian, and Hungarian areas.
} 
(2018) exploit the random assignment of students in $7^{\text {th }}$ grade in South Korea across classes, ensuring their estimates are free from homophily. They employ peers' number of older siblings as an instrument for peer BMI, finding an effect of peers' BMI of 0.831. They do not find statistically significant effects of peers' obesity on ego's obesity (neither contemporaneous nor lagged).

Other studies exploit network structure and use friend of friends' but not friend of ego's covariates as instruments for peer BMI. These include Mora and Gil (2013) and Ajilore et al (2014), both of whom study peer effects among adolescents in school settings, in Spain and the US respectively. The instrumental variable marginal effects on nominated friends' BMI are 0.371 in Mora and Gil (2013) and 0.416 in Ajilore et al (2014). To address correlated effects, the former study adjusts for school and neighborhood fixed effects, while the latter controls for network fixed effects. None of the studies addresses the fact that network links are formed endogenously.

Yakusheva et al (2011) and Yakusheva et al (2014) estimate peer effects in weight gain taking advantage of the random assignment of $1^{\text {st }}$ year university students to roommates. The first paper analyzes a small sample of female students $(\mathrm{N}=144)$ at a private Midwestern US university. Ego's weight at the end of freshman year is regressed on the roommate's weight at baseline (prior to exposure), on ego's weight at baseline, and on dormitory fixed effects. Results show a negative and statistically significant peer effect: a one standard deviation increase in the roommate's past weight decreases ego's weight gain by 0.07 standard deviations. Together with evidence on positive peer influences in exercise frequency, choice of a meal plan, and use of weight loss supplements, the authors attribute the negative peer effect in weight gain to a higher engagement of female students who weigh more in weight management behaviors, and to a transmission of these behaviors to their peers. Results need to be interpreted with 
caution due to the small sample size.

Yakusheva et al (2014) estimate a similar model, but using a larger sample of male and female first year students at two universities. They regress ego's weight at the end of the academic year on peers' and own weight at baseline, ego's and peer's height at baseline, environmental preferences and university fixed effects. They find that peer's weight at baseline increases ego's weight gain by 0.034 for females, but has no influence on males. The influence of alter's weight is stronger for female egos with higher weight than the alter, lower socioeconomic status, and less sexual experience. Influence is stronger also across pairs of roommates with similar academic achievement and similar political and religious views. The authors find little evidence of peer effects on exercise and eating-related behaviors and no alteration of the peer effect on weight estimates after controlling for these potential behavioral mechanisms.

Auld (2011) infers social interactions in BMI and obesity from excess variance across regions and from contrasts between regression coefficients at the individual and aggregate levels (Glaeser et al 2003). The reference group is defined as individuals in the same county (or state) as the ego. Estimated multipliers from the regression analyses are less than 1 or even negative, suggesting biases due to unobserved time-varying influences on body weight at the county or state level. Overall, the results do not suggest the presence of large social multipliers on body weight.

Finally, Cawley et al (2017) exploit genetic information to identify peer effects in BMI and obesity among siblings. The authors run pooled OLS regressions of ego's BMI (or obesity) on a sibling's genetic risk score for obesity, conditional on ego's genetic risk score and other covariates. They find that a one-unit increase in the genetic risk score of the alter is associated with a 0.16 unit increase in ego's BMI and with a 0.97 percentage point increase in the probability of obesity. The alter's genetic risk score is 
significantly correlated with ego weight only when the ego is younger than the alter. ${ }^{8}$

A number of studies find significant peer effects in exercise and food consumption (see Table 3). Carrell et al (2011) study peer effects in a sample of 460 students entering the US Air Force Academy, who are randomly assigned to squadrons. Results show that a one standard deviation increase in the squadrons' average fitness score during high school increases ego's fitness gain by 0.129 standard deviations while in the academy, conditional on ego's past high school fitness score and graduation class fixed effects. This effect is $30 \%$ as strong as the effect of own high school fitness in college fitness. Egos in squadrons with peers with higher fitness scores in high schools have lower probabilities of failing the Academy's fitness requirements. These peer effects are caused primarily by friends who are the least fit. Babcock and Hartman (2010) use experimentally-induced differences in the number of friends of ego exposed to a pay-toexercise treatment in a university setting to study how peer usage of exercise facilities affect ego's usage. For treated egos, they find that an additional treated friend increases the number of visits to an exercise facility by 0.13 , whereas an additional non-treated friend decreases the number of visits by 0.065 . No peer effects are found for untreated individuals.

Ali et al (2011) study peer effects in weight related behaviors using Add Health data from waves 1 and 2. They estimate OLS and probit regressions of ego's behavior on nominated friends' average behavior, controlling for contemporaneous and lagged measures of ego's and peers' BMI, parental location preferences, individual and peer covariates, and school fixed effects. They find peer effects of 0.079 in the likelihood of

\footnotetext{
${ }^{8}$ Ludwig et al (2011) study the effects on overweight and obesity of participation in the Moving to Opportunity (MTO) project, a US initiative that randomly assigned housing vouchers to poor families conditional on their moving to low-poverty areas. Families who moved were less likely to be obese and had lower BMIs. While these results could be indicative of social influence, they could also reflect environmental features, such as better access to healthy food or gyms.
} 
exercising at least three times a week, of 0.184 in the likelihood of practicing active sports, of 0.178 in the number of days per week eating in fast food restaurants, and of 0.066 in the likelihood of eating snacks. These estimates do not address the reflection problem.

Bramoullé et al (2009), Leonard et al (2014), and Fortin and Yazbeck (2015) exploit network intransitivity to estimate peer effects in the number of recreational facilities, food consumption, and frequency of fast food visits, respectively. Using Add Health data, and controlling for network fixed effects, Bramoullé et al (2009) find that a one unit increase in the average number of recreational activities of self-nominated friends increases ego's number of recreational activities by 0.467 . Leonard et al (2014) study a community of low-income, minority individuals in the US. Controlling for network and environmental characteristics, they estimate a positive peer effect of 0.679 of geographically close family and friends on ego's consumption of fruits and vegetables. Fortin and Yazbeck (2015) find that an additional average visit per week of nominated friends to fast food restaurants increases ego's number of visits by 0.129 days. Their model introduces network fixed effects and peers' contextual effects.

Finally, in a study outside economics, Cruwys et al (2015) analyze 69 experiments in which researchers independently manipulated the eating behavior of a social referent and measured either food choice or intake. They find evidence of peer influence (or "modelling effects") in 64 of these studies, despite substantial diversity in methodology, food type, social context, and participant demographics.

\subsection{Peer effects in risky sexual behavior and unwanted pregnancy}

Table 4 depicts a series of papers dealing with peer effects in risky sexual behavior and unwanted pregnancy. One of the first studies to discuss these issues was the paper by Case and Katz (1991), where the authors examine the influence of inner-city low-income 
neighbors in adolescent non-marital pregnancy. Using both probit and IV specifications, the authors find neighbors' influence to be irrelevant for out-of-wedlock pregnancy.

Yakusheva and Fletcher (2015) and Fletcher and Yakusheva (2016) explore peer effects in fertility at the school level. In the former study, they use a friend's miscarriage as a quasi-random fertility shock to peer fertility. They find that a close friend's teen birth is associated with a 6 percentage point reduction in the probability of own teen pregnancy. The negative peer effect suggests a knowledge-sharing mechanism behind the peer influence, rather than a conformity effect. In the latter paper, Fletcher and Yakusheva (2016) use peer-level teen childbearing of mothers and peers' average age of menarche to instrument for peers' fertility. They find large peer effects: a 10 percentage point increase in peer pregnancies is associated with a 2 to 5 percentage point increase in the probability of own-pregnancy. They argue that the influence of peers may occur through the construction of social norms rather than through information and knowledge sharing about pregnancy risks.

Two other papers explore schoolmates' influence on teen fertility choices, but instead of focusing on endogenous effects, they run reduced form specifications that associate students' school or class composition with teen fertility decisions. After using instrumental variables techniques to address selection, Evans et al (1992) find that the fraction of economically disadvantaged students at school is not associated with the ego's likelihood of having a teenage pregnancy. Black et al (2013) exploit variation in cohort composition within schools over time in Norway. They find that a higher fraction of female classmates decreases teen pregnancy by 1.8 percentage points. They do not find statistically significant effects of peers' age or socioeconomic status.

Kuziemko (2006) and Monstad et al (2011) analyze peer effects in childbearing within the family. Kuziemko (2006) runs a model of ego's childbearing on siblings' prior 
fertility decisions conditioning on individual and age-in-years fixed effects. She finds that the probability of having a child increases by $15 \%$ during the 24 months following the birth of a niece or nephew. Monstad et al (2011) exploit an educational reform in Norway that increased the minimum school leaving age to instrument for an older sister's likelihood of having a teen pregnancy. They find evidence of strong peer effects in teen pregnancies across female siblings.

Several other papers analyze directly peer effects in sexual behavior at school. Fletcher (2007), Ali and Dwyer (2011), Halliday and Kwak, Card and Giuliano (2013) and Richards-Shubik (2015) explore whether classmates or school friends can influence adolescent sexual activity initiation. Fletcher (2007) finds that a 10 percentage point increase in the rate of sexual activity at the school level increases the likelihood that a student initiates sex by 3 percentage points. Peer effects differ by age and race. Ali and Dwyer (2011) explore the role of close friends in influencing adolescent sexual initiation. The authors pursue an IV estimation strategy combined with school-level fixed effects and find that a 10 percentage point increase in the fraction of close friends initiating sex increases the individual's probability of sexual initiation by 4 percentage points. Halliday and Kwak (2012) do not find evidence of peer effects in sexual initiation in a model that uses school friends' family background characteristic to instrument for friends' sexual initiation. Richards-Shubik (2015) uses Add Health data to estimate an equilibrium model for the market of sexual partners in high school in the US. The author finds evidence of large peer effects on the timing of sexual initiation, driven by within-gender peer norms. Richards-Shubik's counterfactual simulations indicate that, when peer effects are removed, the number of boys and girls that initiate sexual activity during high school drops by $26 \%$ and 20\%, respectively. Card and Giuliano (2013) analyze peer influence in sexual initiation by running a discrete choice structural model of endogenous peer 
interactions. Their results show that the likelihood that one friend initiates intercourse within a year is increased by about 5 percentage points (on a base rate of 14 percent) if the other one also initiates intercourse.

Finally, two studies use randomly assigned peers to study peer influence in sexual behavior in college. Duncan et al (2005) estimate the effect of having a college roommate who had sex in high school on the number of partners with whom the ego has sex during the first year of college. Eisenberg et al 2014 analyze how the number of sexual partners that the roommate had in high school affects the ego's number of sexual partners in freshman year. Both studies use data from US universities and fail to reject the null of no peer effects.

\subsection{Peer effects in mental health}

Mental illness is severely undertreated worldwide. The lack of knowledge regarding signs and symptoms, ignorance about how to access treatment, and stigma are among the main reasons for this treatment gap. Golberstein et al (2016) use college housing assignment data to study peer effects in the use of mental health services. The study finds evidence of peer influence when groups are defined at the hall level, but not at the room level. The paper finds that exposure to a higher proportion of peers with a recent history of mental health treatment is associated with ego's more positive beliefs about treatment effectiveness.

Some studies have found evidence suggesting that mental health may also be contagious among peers (see Table 5 for a review). Fowler and Christakis (2008) investigate whether happiness can spread from person to person in large social networks, reporting that friends who live within a mile and become happy increase the probability that ego is happy by $25 \%$. This correlation increases to $42 \%$ when the alter who becomes happy lives less than half a mile away. Rosenquist et al (2011) find also 
that individuals are $93 \%, 43 \%$ and $37 \%$ more likely to be depressed if the person they are connected to is depressed, considering one, two and three degrees of separation, respectively.

One of the main limitations of these studies is that they do not control sufficiently for correlated effects. In fact, when scholars address this problem, results indicate weaker links than suggested by previous studies. Taking advantage of the random assignment of first-year college students to roommates, Eisenberg et al (2013) find no evidence of overall contagion of mental health, and evidence of small effects for specific mental health measures. They find no peer influence in happiness and modest influence in anxiety and depression. Pachucki et al (2015) exploit longitudinal data on social interaction patterns to study peer effects in mental health among early adolescents. While they find evidence of cross sectional correlations in mental health status across students in the same network, they find no evidence that connected students' mental health status becomes more similar over time because of their network interactions. In line with these two studies, Ho (2017) finds no evidence of sibling spillovers in health symptoms that could have mental causes, such as loss of appetite or stomach pain. Taking advantage of sibling pairs who attend different schools, Ho instruments the health of a sibling by that of his or her classmates to identify a potential spillover effect. Among other findings, the study shows that "the spillover effect for a depressed sibling pair is significantly smaller than the spillover effect for a typical sibling pair, which implies that it is unlikely that spillovers in the associated symptoms are due to spillovers in depression" (Ho 2017, p. 99). ${ }^{9}$

\footnotetext{
${ }^{9}$ Kling et al (2007) and Ludwig et al (2013) find estimates of neighborhood effects in mental health that could result either from social interactions or from changes in the environment. Both studies analyze the Moving to Opportunity (MTO) project, a large-scale randomized social experiment that offered housing vouchers to poor families with children, conditional on their moving to low-poverty neighborhoods. Four to seven years after the random assignment, adults and female youths in families offered the vouchers showed substantial mental health benefits -related to distress, depression, anxiety,
} 


\section{Mechanisms and policy implications}

\subsection{Externalities in preferences, beliefs, and constraints}

Despite the relatively large evidence on the existence of strategic complementarities in health behaviors across a wide range of behaviors, populations, reference group, and estimation techniques, there is not yet a good understanding of the underlying mechanisms. The literature has proposed three channels for peer effects in health behaviors (Rice and Sutton 1998, Cutler and Glaeser 2010, Nakamura et al 2017): (i) social spillovers in preferences (direct social interactions or payoff interactions); (ii) social spillovers in beliefs (social learning); and (iii) social spillovers in constraints.

The first channel, direct social interactions or payoff interactions can arise for several reasons. An individual's utility from an action may be enhanced when others take the same action. Eating and drinking are examples of health-related behaviors that usually satisfy this condition (Cutler and Glaeser 2010). In general, we prefer to eat with others than by ourselves. And if our friends go for a drink, our expected return from drinking rises. We refer to this motive as social contagion. In addition, preferences may be shaped by the comparison of one's actions or outcomes to those of a peer or reference group. Deviating from the social norm established by the reference group decreases utility, either because the group explicitly penalizes the individual or because deviating decreases individual implicit outcomes, such as social prestige or inclusion (e.g. I choose to drink because if I do not, I will not be invited to the pub next times my friends gather together). We refer to this motive as preference for conformism.

calmness, and sleep. Ten to fifteen years after program implementation, these effects persisted among girls. The leading hypothesis is that moving away from dangerous neighborhoods substantially reduced the levels of stress faced by families. 
Furthermore, spillovers in preferences could take place due to a purely imitative process if individuals have bounded rationality and for example, have preference uncertainty.

The second mechanism for peer influence, social learning, considers that the actions of others can be informative about the costs and benefits of one's health-related choices (Bandura 1977, Bikhchandani et al 1992). In these models, the presence of friends who drink or smoke may provide evidence regarding the benefits of these activities. On the other hand, an environment in which nobody drinks or smokes could be considered an indication that these activities are not good choices.

The third mechanism takes place when the costs of taking an action decrease as the number of individuals taking that same action increases (network externalities). These are market-mediated externalities caused by the existence of fixed costs. A healthy food supermarket chain may require a critical mass of consumers to open a store in an area. Unless this critical mass is achieved, consumption of healthy food may be prohibitively expensive. Alternatively, a kid in school that only likes to play soccer may find it hard to exercise if only a few other kids in the school like soccer. Network externalities can also take place when joint childbearing decreases the costs of raising a child, because of shared resources, for example.

\subsubsection{Social interaction mechanisms in body weight}

Most studies have attributed peer effects in health-related behaviors to direct social interactions, either directly through influences in weight management behaviors or indirectly through social norms about the acceptability of body weight. This line of research gained especial attention due to the studies by Christakis and Fowler (2007, 2008a, 2008b, 2009), who claimed that different behaviors and conditions (including smoking, obesity and happiness) can spread by contagion through large social networks. Christakis and Fowler's (2007) influential and controversial study on obesity concluded 
that peer effects are one of the culprits of the American obesity epidemic.

We already described in section 3.2 a set of studies showing evidence of peer influence in individual's weight related behaviors. These studies suggest that social influences in food choices, food intake, and energy spending are a likely explanation for the observed peer effects in body weight. However, it is not clear whether the influence operates first through body weight norms and spills over to weight related behaviors, or the other way round. A few papers fail to find a mediating role for weight related behaviors in the explanation of peer influence in body weight (Fletcher and Yakusheva 2016, Cawley et al 2017).

Many studies are in line with the idea that the willingness to conform to social norms is a key driver of peer effects in obesity. Graham and Felton (2005) suggest that changes in norms about appearance are key to explaining the variance in obesity incidence across socioeconomic cohorts in the United States. Eisenberg and Quinn, (2006) show that being part of a social group where other members recently gained weight leads an individual to adopt obesity-related behaviors. Etilé (2007) analyzes whether social norms about ideal body weight (calculated by averaging individual perceptions of the ideal BMI over all observations within a reference group) predict individual's perceptions of ideal body weight and individual's food choices (e.g., alcohol, fat, sugar). He finds suggestive evidence that social norms and habitual BMI affect ideal BMI, which in turn influence food choices and, ultimately, actual BMI. His estimates imply that social norms of body shape are not resistant to changes in actual body weight. Blanchflower et al (2009) provide evidence that perceptions of overweight depend on peers' BMI among adults. Nie et al (2015) find that female Chinese teenagers whose peers have a higher BMI are, other things equal, less likely to consider themselves overweight. In a study of young women in Europe, Costa-Font and Jofre- 
Bonet (2013) show that the larger peers' body mass, the lower the likelihood of being anorexic. Gwozdz et al (2015) find that parents are more likely to misperceive their children as being thinner than they actually are as the peers' BMI increases.

Interestingly, several papers suggest that social norms may affect preferences interactively rather than additively. In Pliner and Mann (2004), participants in an experiment eat more when led to believe that prior participants have eaten more. This effect is only present when individuals received palatable, rather than unpalatable, food. Babcock and Hartman (2010) show that study subjects who have been incentivized to increase gym usage, exercise more if they have more treated friends, whereas control subjects are not influenced by their treated or untreated peers. Yang and Huang (2014) find that an individual is likely to gain weight as his/her number of obese friends increases, but is unlikely to lose weight as the number of obese friends decreases.

\subsubsection{Mechanisms behind social interactions in substance use}

Social norms can also be key in explaining social interactions in behaviors such as alcohol, tobacco or drug use, although most of the literature on mechanisms does not come from economics (Chen, Chang and He 2003, Stormshak et al 1999). Several authors posit that adolescents use substances to gain recognition and maintain their status among peers (Mitchell and Amos 1997, Gaviria and Raphael 2001, Plumridge, Fitzgerald and Abel 2002, Prinstein and Cillessen 2003, Prinstein, Meade and Cohen 2003). Deviators (those who dare to say no) are likely to be punished through "ostracism or merciless bullying," a mechanism that creates strong incentives to conform. Using Add Health data, Balsa et al (2010) show that adolescents are socially rewarded for conforming to their peers' alcohol use and penalized (to a lesser degree) for increasing their consumption above that of their peers. Male adolescents are rewarded for keeping up with their peers' drinking and for getting drunk, while female 
adolescents are rewarded for drinking per se, but not necessarily for keeping up with their peers.

DeCicca et al (2008) provide evidence in support of social norms as a key determinant of peer effects in smoking choices. The authors show that a social antismoking sentiment is more important than cigarette prices when it comes to explain youth smoking participation. According to DeCicca et al (2008, p. 745), "initiation decisions are typically made in adolescence and may be driven more by the desire for peer acceptance and other non-economic factors," whereas "economic factors may play more of a role in decisions about cessation and daily demand”. Rodríguez-Planas and Sanz-de-Galdeano (2016) find that second-generation immigrant teenage-girls with more gender equality in the country of ancestry are, ceteris paribus, relatively more likely to smoke, drink and use drugs than boys. ${ }^{10}$

Finally, there is evidence that social norms about substance use do not necessarily coincide with habitual prevalence. Adolescents are likely to perceive smoking or drinking behavior by their peers to be more salient than it really is (Reid et al 2008, Steffian 1999). Thus, teenage substance use may stem from a combination of inadequate beliefs and a taste for conformity.

\subsubsection{Mechanisms behind social interaction in teen sexual activity and} pregnancy

As with other health behaviors, most studies attribute peer effects in teen pregnancy to social norms. Case and Katz (1991) and Fletcher and Yakusheva (2012) argue that exposure to high rates of adolescent pregnancy reduces the stigma cost of being a teenage mother, leading thus to higher rates of teenage pregnancy.

\footnotetext{
${ }^{10}$ Given that these and other risk behaviors are usually associated with boys, the authors suggest that moving towards gender equality may have the unintended spillover of making girls relatively more prone to engage in unhealthy behaviors.
} 
In some particular cases, however, the sign of the endogenous peer effect can be informative of social learning effects. If network externalities are not able to generate congestion effects, a negative correlation in peer behavior might indicate that peer effects are mainly responding to information mechanisms. One interesting example is the paper by Yakusheva and Fletcher (2015), where the probability of teen pregnancy drops after the realization of a close friend's teen birth. As the authors explain, "we might imagine the possibility of a large amount of learning about the difficulties of being a teen mother if a high school friend has a child," (p. 29). The paper uses three different strategies to support the hypothesis of knowledge externalities. First, the negative peer effect is larger in schools with low fertility rates. Teenagers are expected to learn more from the teen childbearing experience of a peer in school as the rate of teen childbearing is smaller. Second, the peer effect increases when excluding women with a childbirth, who are expected to get less information from the experience of peers. Third, the treatment effect is smaller when the friend's partner is ready to assume the parenting role: the harder the experience of peers, the larger should information externalities be.

Kuziemko (2006) also claims that social learning is likely to underlie her findings of peer influence across sibling in fertility decisions. She bases her claim on evidence that social influence is stronger for couples having their first baby, a result suggesting that new information is especially valued among non-experienced parents.

In addition, both Kuziemko (2006) and Monstad et al (2011) suggest a role for network externalities behind peer influence in fertility across siblings, which would take place if siblings find it easier to share childrearing, information, and other resources when having a child within the same period.

\subsection{Average vs. aggregate effects}


When discussing direct social interactions, scholars usually think in terms of localaverage models: peer behavior is viewed as the "social norm", imposing a cost when individuals deviate from it. If that is the case, we should expect agents to conform to the average behavior of the reference peer group. Nonetheless, peer effects may also respond to the sum of peer efforts: the more friends involved in a particular activity, the higher the expected return from it. These are local-aggregate effects. The distinction between average and aggregate effects is far from being a minor issue, since these alternative models have substantially different policy implications. If we believe peer effects respond to the local-aggregate model, then the most effective policy would focus on one or more key agents. If we believe instead that the local-average model is the most appropriate to describe endogenous peer effects, adequate policies must tackle the norm of the group. In such case, policies must change the group perception regarding what should be considered a normal or appropriate behavior.

As discussed, the literature has put the spotlight on local-average effects when estimating and analyzing the mechanisms for health-related peer effects. It is worth asking whether that is the correct model. Liu et al (2014) estimate a model allowing for two types of peer effects: average effects and aggregate effects. While average effects do not depend on the number of peers taking the action, aggregate effects do. Employing network intransitivity properties as well as measures of network centrality to identify both effects, the authors show that both social norms and aggregate effects explain peer effects in sports activities. Ajilore et al (2014) also attempt to distinguish aggregate from average local effects in a model of peer effects in obesity and overweight. They find significant peer interactions in body mass index, which can be explained by both mechanisms of peer influence; the local average effect (social norm) is, however, much larger than the social aggregate effect. Peer influence for overweight 
status, on the other hand, appears to operate solely through social aggregate effects.

Some other studies suggest indirectly that the local-aggregate model might be suitable for peer effects in health-related behaviors. For example, Robalino (2016) uses Add Health data to analyze peer effects on cigarette smoking. He finds that the smoking propensity of the $20 \%$ most popular kids account for most of the aggregate peer effects on smoking, an effect that tends to persist over years.

\subsection{Mechanisms dealing with network structure}

Aiming for a better understanding of how health related behaviors can spread through social networks, scientists have developed theories on how network topology may affect this process. A notable example is the paper by Jackson et al (2017), who suggest a taxonomy of networks characteristics, discussing the economic consequences of different social network structures. More precisely, the authors develop a framework that underscores four major network characteristics: degree distributions, homophily patterns, clustering and centrality of nodes. The degree of an agent is the number of connections to other agents. Homophily refers to the tendency of individuals to select similar individuals. Clustering measures the local dependence among the locations of the different links in a social network. And centrality usually refers to the degree of popularity of a particular agent in a given network. While Jackson et al do not pay particular attention to health-related behaviors, scholars have found evidence of the importance of these characteristics when analyzing peer effects in health.

Homophily is a notable example. Peer similarity is not only a good predictor of connection between individuals, but also tells us about the potential relative strength of peer effects. Our review finds evidence of differential peer effects for individuals with different traits. For instance, Argys and Rees (2008) and Sen (2009) find different peer 
influence in smoking for males and females, whereas Yakusheva et al (2014) find that peers' weight increases ego's weight gain for females, but has no influence on males ${ }^{11}$.

Centola (2011) studies the role of homophily in the process of adoption of healthrelated behaviors and innovations. He notices that the degree of similarity in social contacts can help promote diffusion, but can also exclude less healthy individuals from interactions with healthier peers. Conducting an internet-based social network experiment, Centola shows that those networks with more homophilous ties (i.e., where individual are clustered by gender, age and body mass index) exhibit more adoption than fully integrated networks (i.e., where participants are randomly mixed, regardless of individual traits). Moreover, the results show homophily does not restrict adoption of a health behavior only to healthier individuals, but instead increases the adoption by those who are most in need to adopt it. In line with Centola (2011), Yakusheva et al (2014) find that peer effects in weight gain are stronger across peers with similar academic achievement and similar political and religious views.

Taking advantage of the same controlled experiment, Centola (2010) also shows the relevance of another characteristic highlighted by Jackson et al (2017): clustering. According to his findings, the greater the clustering of the network topology, the more effective and faster these networks are in spreading a particular health-related behavior (i.e., to more people and in less time). This result supports Centola and Macy's (2007) statement that people usually need multiple adopters to convince themselves to implement a given health behavior ${ }^{12}$. Interestingly, Centola (2010) also shows that

\footnotetext{
${ }^{11}$ On the other hand, some scholars have not been able to distinguish differential peer effects in healthrelated behaviors for females and males (e.g., Clark and Lohéac 2007).

12 According to Aral and Nicolaides (2017), there are three theories that associate network structure with behavioral contagions: (i) Centola and Macy's (2007) Complex Contagion theory indicates that, in order to induce a costly behavior (e.g., to exercise, to follow a diet pattern), individuals usually demand a signal of adoption by different peers and hence, clustered networks are more likely to spread these complex contagions; (ii) Ugander et al (2012) suggest the Structural Diversity theory, arguing that structural diversity (i.e., the number of unconnected clusters that have at least one adopter) is key to explaining
} 
social networks with more clustering are better for spreading a health behavior widely, even if the maximum distance across all pairs of nodes is larger than in other social structures (i.e., it has a larger diameter).

While most studies treat links between nodes as binary values (i.e., they can be “on” or “off”, Jackson et al 2017, pp. 64-65), empirical evidence suggests that we should incorporate link heterogeneity and distinguish weak ties from strong ones (Granovetter 1973). Peer influence might be stronger between peers in reciprocated friendships (or undirected links), whereas the non-reciprocated (or directed) links are associated with weaker peer effects (e.g., Card and Giuliano 2013, Christakis and Fowler 2007, Fowler and Christakis 2008).

Another way to incorporate heterogeneity in peer influence is by considering different hierarchical statuses. According to this approach, peer influence will depend on the relative standings of agents, where peers of higher status are expected to be the influencers, and those with lower statuses are expected to be the adopters. The studies by Yakusheva et al (2014), Robalino (2016), and Cawley et al (2017) find evidence of hierarchical peer effects in weight gain, smoking, and BMI, respectively. In Yakusheva et al (2014), students are more likely to be influenced by peers that are slimmer, of higher socioeconomic status, and more sexually experienced relative to themselves. In Robalino (2016) only the $20 \%$ of the distribution with higher status exerts a significant influence on others. Cawley et al (2017) shows that peer influences on body weight work from older to younger siblings.

\subsection{Peer effects in economic fundamentals}

Finally, rather than focusing on direct influences in behavior, peer effects in health behaviors could result from peer influence in economic fundamentals. For example, 
peers may have similar attitudes towards substance use or sexual behavior because they exert an influence on each others' risk attitudes or time preferences. Exploiting random assignment of MBA students to peer groups, Ahern et al. (2012) find positive peer effects in risk aversion, which they attribute to a desire for conformity. Balsa et al (2015) estimate peer effects in risk attitudes in a sample of high-school students. Identification of peer effects is based on parents not being able to choose the class within school, and on the use of instrumental variables conditional on school-grade fixed effects. They find a significant and quantitative large impact of peers' risk attitudes on male individuals' coefficient of risk aversion, but not on womens'.

\section{Conclusions}

In this paper we review the economic literature on peer effects in health behavior and conditions from the last 20 years. We review studies exploring social influence across college roommates, air force squadrons, students in the same school, school-year, or class, spouses, siblings, and network-nominated close friends. Most studies use data from developed countries (US and Europe). There is very little evidence for developing regions. Regarding the outcomes, most papers on substance use focus on dichotomous indicators of current use, while the body weight literature relies on measures of BMI, overweight and obesity. Teen pregnancy and initiation of sexual activity are the preferred outcomes in the study of peer effects in sexual behavior, and indicators of mental health use and of mental health conditions (depression, anxiety) prevail in the mental health literature. Almost all papers consider linear-in-means specifications of peer influence.

We argue that no single econometric technique has solved for all the challenges involved in the estimation of peer effects. However, there is consistence evidence of social influence in alcohol use, body weight, weight related behaviors, teen pregnancy, 
and teen sexual initiation across a wide range of populations, reference group definitions, and estimation techniques. The evidence is mixed, on the other hand, for tobacco, illicit drug use, and mental health conditions, although there is some evidence of positive peer effects in the utilization of mental health services.

Despite the widespread evidence on the existence of strategic complementarities in health behaviors, we still know little about the mechanisms behind peer influence. Because a large body of studies rely on the use of peers' family background characteristics for identification, we are unable to determine in these cases whether the effects reflect endogenous or contextual influence. Recent efforts have turned the spotlight on network structure and how it might impact the underling mechanisms of social interactions and peer influence. While these efforts are promising, the literature has yet to advance in addressing the endogenous formation of network links.

Understanding the mechanisms behind peer influence is key to the design of effective policies, as each mechanism has different implications in terms of how to promote healthy behaviors. Nakamura et al (2017) provide a good summary of the policy implications triggered by different sources of peer effects. If individuals learn from others about the potential health consequences of their behavior, the most appropriate policy would be to design educational policies that provide information about the consequences of others' health-related behavior. As Nakamura et al notice, empirical evidence indicates that over-estimation of peer smoking prevalence is a key determinant of smoking for adolescents (Reid et al 2008). Providing information about real prevalence may contribute to adjust adolescents beliefs.

If, on the other hand, peer effects stem primarily from social comparisons, providing information about the "right" behavior would not work. In this context, 
Nakamura et al suggest manipulating the incentive system to increase the opportunity cost of conforming (e.g., punishing unhealthy behaviors or subsidizing healthy options).

Finally, if individuals face a decrease in their utility when they are seen as deviating from certain social norms, a possible solution would be to manipulate the perceived norm. In this case, Nakamura et al's suggestion is to take advantage of media power on individual's perception regarding what others consider desirable and, for instance, campaigning to modify the normatively justified belief about the way people ought to behave. Leonard et al (2009) propose geography-specific social marketing and education campaigns to address social norms related to diet patterns, as well as the type of food provided by non-profit agencies and peer behavior. Christakis and Fowler (2008) suggest focusing on group-level interventions, in particular programs that create artificial social network ties (e.g. Alcoholics Anonymous, weight loss groups, symptom support groups).

A deeper comprehension of the mechanisms behind peer influence and the use of this understanding to develop policy recommendations constitute the main challenges of the research agenda in peer effects for the years to come. 


\section{References}

Ajilore, O., Amialchuk, A., Xiong, W., \& Ye, X. (2014). Uncovering peer effects mechanisms with weight outcomes using spatial econometrics. The Social Science Journal, 51(4), 645-651.

Ajilore, O., Amialchuk, A., \& Egan, K. (2016). Alcohol consumption by youth: Peers, parents, or prices? Economics \& Human Biology, 23, 76-83.

Akerlof, G.A., \& Kranton, R.E. (2000). Economics and Identity. Quarterly Journal of Economics, 115, 715-754.

Ali, M.M., \& Dwyer, D.S. (2011). Estimating Peer Effects in Sexual Behavior among Adolescents. Journal of Adolescence, 34, 183-190.

Ali, M.M., Amialchuk, A., \& Dwyer, D.S. (2011). The social contagion effect of marijuana use among adolescents. PLoS One, 6(1), e16183.

Ali, M.M., Amialchuk, A., \& Heiland, F.W. (2011). Weight-related behavior among adolescents: the role of peer effects. PLoS One, 6(6), e 21179.

Aral, S., \& Nicolaides, C. (2017). Exercise Contagion in a Global Social Network. Nature Communication, 8, 14753.

Aral, S., \& Walker, D. (2012). Identify Influential and Susceptible Members of Social Networks. Science, 337, 337-341.

Argys, L.M., \& Rees, D.I. (2008). Searching for peer group effects: A test of the contagion hypothesis. The Review of Economics and Statistics. 90(3), 442-458

Auld, M.C. (2011). Effect of large-scale social interactions on body weight. Journal of Health Economics, 30(2), 303-316.

Babcock, P. S., \& Hartman, J. L. (2010). Networks and workouts: Treatment size and status specific peer effects in a randomized field experiment. Working Paper No. w16581. National Bureau of Economic Research.

Balsa, A.I., Homer, J.F., French, M.T., \& Norton, E.C. (2011). Alcohol use and popularity: Social payoffs from conforming to peers' behavior. Journal of Research on Adolescence, 21(3), 559-568.

Balsa, A.I., French, M.T., \& Regan, T.L. (2014). Relative deprivation and risky behaviors. Journal of Human Resources, 49(2), 446-471.

Balsa, A. I., Gandelman, N., \& González, N. (2015). Peer effects in risk aversion. Risk Analysis, 35(1), 27-43.

Balsa, A.I., Gandelman, N., \& Roldán, F. (2018). Peer and parental influence in academic skills and risky behavior. Working paper series 2018. Universidad de Montevideo.

Banerjee, A.V. (1992). A Simple Model of Herd Behavior. The Quarterly Journal of Economics, 107(3), 797-817.

Bifulco, R., Fletcher, J.M., \& Ross, S.L. (2011). The Effect of Classmate Characteristics on Post-secondary Outcomes: Evidence from the Add Health. American Economic Journal: Economic Policy, 3(1), 25-53. 
Bikhchandani, S., Hirshleifer, D., \& Welch, I. (1992). A Theory of Fads, Fashion, Custom, and Cultural Change as Informational Cascades. Journal of Political Economy, 100(5), 992-1026.

Black, S.E., Devereux, P.J., \& Salvanes, K.G. (2013). Under pressure? The effect of peers on outcomes of young adults. Journal of Labor Economics, 31(1), 119-153.

Blanchflower, D. G., Van Landeghem, B., \& Oswald, A. J. (2009). Imitative obesity and relative utility. Journal of the European Economic Association, 7(2-3), 528-538.

Bound, J., \& Krueger, A.B. (1991). The extent of measurement error in longitudinal earnings data: Do two wrongs make a right? Journal of Labor Economics, 9(1), 1-24.

Boyd, N.R., Windsor, R.A., Perkins, L.L., \& Lowe, J.B. (1998). Quality of Measurement of Smoking Status by Self-Report and Saliva Cotinine Among Pregnant Women. Maternal and Child Health Journal, 2(2), 77-83.

Bramoullé, Y., Djebbari, H., \& Fortin, B. (2009). Identifi H., \& Fortin, effectsthrough social networks. Journal of Econometrics, 150, 41-55.

Brener, N.D., Billy, J.O., \& Grady, W.R. (2003). Assessment of factors affecting the validity of self-reported health-risk behavior among adolescents: evidence from the scientific literature. Journal of Adolescent Health, 33(6), 436-457.

Brock, W.A., \& Durlauf, S.N. (2001a). Interactions-Based Models. Handbook of Econometrics, 3297-3380.

Brock, W. A., \& Durlauf, S. N. (2001b). Discrete Choice with Social Interactions. Review of Economics Studies, 68, 235-260.

Burkhauser, R.V., \& Cawley, J. (2008). Beyond BMI: The Value of More Accurate Measures of Fatness and Obesity in Social Science Research. Journal of Health Economics, 27(2), 519-529.

Card, D., \& Giuliano, L. (2013). Peer effects and multiple equilibria in the risky behavior of friends. The Review of Economics and Statistics, 95(4), 1130-1149.

Carrell, S.E., Hoekstra, M., \& West, J.E. (2011). Is poor fitness contagious?: Evidence from randomly assigned friends. Journal of Public Economics, 95(7), 657-663.

Case, A.C., \& Katz L.F. (1991). The Company You Keep: The Effects of Family and Neighborhood on Disadvantaged Youth. Working Paper No. 3705, National Bureau of Economic Research.

Cawley, J., \& Burkhauser, R.V. (2006). The Importance of Objective Health Measures in Predicting Early Receipt of Social Security Benefits: The Case of Fatness. Working Paper No. wp148, University of Michigan, Michigan Retirement Research Center.

Cawley, J., Han, E., Kim, J. J., \& Norton, E. C. (2017). Testing for peer effects using genetic data (Working Paper No. w23719). National Bureau of Economic Research.

Centola, D. (2010). The Spread of Behavior in an Online Social Network Experiment. Science, 329(5996),1194-1197.

Centola, D. (2011). An Experimental Study of Homophily in the Adoption of Health Behavior. Science, 334(6060), 1269-1272.

Centola, D., \& Macy, M. (2007). Complex Contagions and the Weakness of Long Ties. American Journal of Sociology, 113, 702-734. 
Chen, X., Chang, L., \& He, Y. (2003). The peer group as a context: Mediating and moderating effects on relations between academic achievement and social functioning in Chinese children. Child Development, 74, 710-727.

Christakis, N.A., \& Fowler, J.H. (2007). The Spread of Obesity in a Large Social Network over 32 Years. New England Journal of Medicine, 357(4), 370-379.

Christakis, N.A., \& Fowler, J.H. (2008a). The Collective Dynamics of Smoking in a Large Social Network. New England Journal of Medicine, 358(21), 2249-2258.

Christakis, N.A., \& Fowler, J. H. (2008b). Dynamic spread of happiness in a large social network: longitudinal analysis over 20 years in the Framingham Heart Study. British Medicine Journal, 337a:2338.

Christakis, N. A., \& Fowler, J. H. (2009). Connected: The Surprising Power of our Social Networks and how they Shape our Lives. New York: Little, Brown.

Clark, A.E., \& Etilé, F. (2006). Don't give up on me baby: Spousal correlation in smoking behaviour. Journal of Health Economics, 25(5), 958-978.

Clark, A.E., \& Lohéac, Y. (2007). "It wasn't me, it was them!" Social influence in risky behavior by adolescents. Journal of Health Economics, 26(4), 763-784.

Cohen-Cole, E., \& Fletcher, J.M. (2008). Is obesity contagious? Social networks vs. environmental factors in the obesity epidemic. Journal of Health Economics, 27(5), 13821387.

Costa-Font, J., \& Jofre-Bonet, M. (2013). Anorexia, Body Image and Peer Effects: Evidence from a Sample of European Women. Economica, 80(317), 44-64.

Cruwys, T., Bevelander, K.E., \& Hermans, R.C. (2015). Social modeling of eating: A review of when and why social influence affects food intake and choice. Appetite, 86, 318.

Cutler, D.M., \& Glaeser, E.L. (2010). Social Interactions and Smoking, NBER Chapters, in: Research Findings in the Economics of Aging (123-141). National Bureau of Economic Research, Inc.

DeCicca, P., Kenkel, D., Mathios, A., Shin, Y., \& Lim Y. (2008). Youth Smoking, Cigarette Prices, and Anti-Smoking Sentiment. Health Economics, 17, 733-749.

Deaton, A. (1995). Data and Econometric Tools for Development Analysis, in Handbook of Development Economics, vol. 3A, ed. Jere Behrman and T.N. Srinivasan. Amsterdam: North Holland.

Duncan, G.J., Boisjoly, J., Kremer, M., Levy, D. M., \& Eccles, J. (2005). Peer effects in drug use and sex among college students. Journal of Abnormal Child Psychology, 33(3), 375-385.

Edoka, I.P. (2017). Implications of Misclassification Errors in Empirical Studies of Adolescent Smoking Behaviours. Health Economics, 26(4), 486-499.

Eisenberg, D., Golberstein, E., \& Whitlock, J.L. (2014). Peer effects on risky behaviors: New evidence from college roommate assignments. Journal of Health Economics, 33, 126-138.

Eisenberg, D., Golberstein, E., Whitlock, J.L., \& Downs, M.F. (2013). Social Contagion of Mental Health: Evidence from College Roommates. Journal of Health Economics, 22(8), 965-986. 
Eisenberg, D., \& Quinn, B.C. (2006). Estimating the effect of smoking cessation on weight gain: an instrumental variable approach. Health Service Research, 41, 2255-2266. Etilé, F. (2007). Social Norms, Ideal Body Weight and Food Attitudes. Health Economics, 16, 945-966.

Evans, W.N., Oates, W.E., \& Schwab, R.M. (1992): Measuring Peer Group Effects: A Study of Teenage Behavior. The Journal of Political Economy, 100(5), 966-991.

Fletcher, J. (2007). Social Multiplier in Sexual Initiation Decisions among US HighSchool Students. Demography, 44(2), 373-388.

Fletcher, J.M. (2010). Social interactions and smoking: Evidence using multiple student cohorts, instrumental variables, and school fixed effects. Journal of Health Economics, 19(4), 466-484.

Fletcher, J.M. (2012). Peer influences on adolescent alcohol consumption: evidence using an instrumental variables/fixed effect approach. Journal of Population Economics, 25(4), 1265-1286.

Fletcher, J., \& Yakusheva, O. (2016). Peer Effects on Teenage Fertility: Social Transmission Mechanisms and Policy Recommendations. American Journal of Health Economics, 2(3), 300-317.

Fortin, B., \& Yazbeck, M. (2015). Peer effects, fast food consumption and adolescent weight gain. Journal of Health Economics, 42, 125-138.

Fowler, J.H., \& Christakis, N.A. (2008). Estimating peer effects on health in social networks: A response to Cohen-Cole and Fletcher; Trogdon, Nonnemaker, Pais. Journal of Health Economics, 27(5), 1400-1405.

Gaviria, A., \& Raphael, S. (2001). School-based peer effects and juvenile behavior. The Review of Economics and Statistics, 83(2), 257-268.

Glaeser, E.L., Sacerdote, B.I., \& Scheinkman, J.A. (2003). The Social Multiplier. Journal of the European Economic Association, 1(2-3), 345-353.

Glaeser, E.L., \& Scheinkman, J.A. (2001). Measuring Social Interactions. In Durlauf, S., \& Young, P. (Eds.), Social Dynamics. Cambridge: MIT Press.

Glovannucci, E., Colditz, G., Stampfer, M.J., Rimm, E.B., Litin, L., Sampson, L., \& Willett, W.C. (1991). The assessment of alcohol consumption by a simple selfadministered questionnaire. American Journal of Epidemiology, 133(8), 810-817.

Golberstein, E., Eisenberg, D., \& Downs, M.F. (2016). Spillover Effects in Health Service Use: Evidence from Mental Health Care using First-Year College Housing Assignments. Journal of Health Economics, 25, 40-55

Graham, G. , \& Felton, A. (2005). Variance in Obesity Across Cohorts and Countries: A Norms-Based Explanation Using Happiness Surveys. Working paper, Brookings Institution.

Granovetter, M.S. (1973). The Strength of Weak Ties. American Journal of Sociology, 78(6), 1360-80.

Gwozdz, W., Sousa-Poza, A., Reisch, L.A., Bammann, K., Eiben, G., Kourides, Y., Kovács, É., Lauria, F., Konstabel, K., Santaliestra-Pasias, A.M., Vyncke, K., \& Pigeot, I. (2015). Peer effects on obesity in a sample of European children. Economics \& Human Biology, 18, 139-152. 
Halliday, T.J., \& Kwak, S. (2009). Weight gain in adolescents and their peers. Economics \& Human Biology, 7(2), 181-190.

Halliday T.J., \& Kwak, S. (2012). What is a peer? The role of network definitions in estimation of endogenous peer effects. Applied Economics, 44(3), 289-302.

Hanushek, E.A., Kain, J.F., Markman, J.M., \& Rivkin, S.G., (2003). Do peer ability affect student achievement? Journal of Applied Econometrics, 18(5), 527-544.

Harris, J.E., \& González López-Valcárcel, B. (2008). Asymmetric peer effects in the analysis of cigarette smoking among young people in the United States, 1992-1999. Journal of Health Economics, 27(2), 249-264.

Hirshleifer, D. (1995). The blind leading the blind. Social influence, fads, and informational cascades. In Tomassi, M. \& Ierulli, K. (Eds.), The New Economics of Human Behaviour. Cambridge: Cambridge University Press.

Ho, C.Y. (2017). Estimating Sibling Spillovers in Health: Evidence on Symptoms. Economics \& Human Biology, 27, 93-101.

Huybrechts, I., De Bacquer, D., Van Trimpont,I., De Backer, G., \& De Henauw, S. (2006).Validity of parentally reported weight and height for pre-school-aged children in Belgium and its impact on classification into body mass index categories. Pediatrics, 118(5), 2018-2109.

Jackson, M. O, Rogers, B. W., \& Zenou, Y. (2017). The Economic Consequences of Social-Network Structure. Journal of Economic Literature, 55(1), 49-95.

Kapinos, K. A., Yakusheva, O., \& Eisenberg, D. (2014). Obesogenic environmental influences on young adults: Evidence from college dormitory assignments. Economics \& Human Biology, 12, 98-109.

Kawaguchi, D. (2004). Peer Effects on Substance Use among American Teenagers. Journal of Population Economics, 17, 351-367.

Kling, J.R., Liebman, J.B., \& Katz, L.F. (2007). Experimental Analysis of Neighborhood Effects. Econometrica, 75(1), 83-119.

Krauth, B.V. (2005). Peer effects and selection effects on smoking among Canadian youth. Canadian Journal of Economics, 38(3), 735-757.

Krauth, B.V. (2006). Simulation-based estimation of peer effects. Journal of Econometrics, 133(1), 243-271.

Krauth, B.V. (2007). Peer and selection effects on youth smoking in California. Journal of Business \& Economic Statistics, 25(3), 288-298.

Kuziemko, I. (2006). Is Having Babies Contagious? Estimating Fertility Peer Effects between Siblings. Working paper, Harvard University.

Leonard, T., McKillop, C., Carson, J. A., \& Shuval, K. (2014). Neighborhood effects on food consumption. Journal of Behavioral and Experimental Economics, 51, 99-113.

Lim, J., \& Meer, J. (2018). How do peers influence BMI? Evidence from randomly assigned classrooms in South Korea. Social Science \& Medicine, 197, 17-23.

Lin, Xu. (2014). Peer Effects in Adolescents' Delinquent Behaviors: Evidence from a Binary Choice Network Model. Regional Science and Urban Economics, 46, 73-92. 
Liu, X., Patacchini, E., \& Zenou, Y. (2014). Endogenous Peer Effects: Local Aggregate or Local Average? Journal of Economic Behavior \& Organization, 103, $39-59$.

Loh, C.A., Li, Q. (2013). Peer effects in adolescent bodyweight: evidence from rural China. Social Science \& Medicine, 86, 35-44.

Ludwig J., Liebman J.B., Kling J.R., Duncan, G.J., Katz, L.F., Kessler, R.C., \& Sanbonmatsu, L. (2008). What Can We Learn About Neighborhood Effects from the Moving to Opportunity Experiment? American Journal of Sociology, 114, 144-188.

Ludwig, J., Sanbonmatsu, L., Gennetian, L., Adam, E., Duncan, G.J., Katz, L.F., Kessler, R.C., Kling, J.R., Lindau, S.T., Whitaker, R.C., \& McDade, T.W. (2011). Neighborhoods, obesity, and diabetes - A randomized social experiment. New England Journal of Medicine, 365(16), 1509-1519.

Lundborg, P. (2006). Having the wrong friends? Peer effects in adolescent substance use. Journal of Health Economics, 25(2), 214-233.

Manski, C.F. (1993). Identification of Endogenous Social Effects: The Reflection Problem. The Review of Economic Studies, 60(3), 531-542.

Manski, C.F. (2000). Economic Analysis of Social Interactions. Journal of Economic Perspectives, 68(3), 115-136.

Manski, C. F. (2005). Social choice with partial knowledge of treatment response. New Jersey: Princeton University Press.

McVicar, D., \& Polanski, A. (2014). Peer effects in UK adolescent substance use: Never mind the classmates?. Oxford Bulletin of Economics and Statistics, 76(4), 589604.

Micklewright, J., Schnepf, S.V. \& Silva, P.N. (2012) Peer effects and measurement error: the impact of sampling variation in school survey data (evidence from PISA). Economics of Education Review, 31(6), 1136-1142.

Mitchell, L., \& Amos, A. (1997). Girls, pecking order and smoking. Social Science and Medicine, 44, 1861-1869.

Monstad, K., Propper, C., \& Salvanes K.G. (2011). Is Teenage Motherhood Contagious? Evidence from a Natural Experiment. Discussion Paper Series in Economics 12/2011, Department of Economics, Norwegian School of Economics.

Mora, T., \& Gil, J. (2013). Peer effects in adolescent BMI: evidence from Spain. Health Economics, 22(5), 501-516.

Moriarty, J., McVicar, D., \& Higgins, K. (2016). Cross-section and panel estimates of peer effects in early adolescent cannabis use: With a little help from my 'friends once removed'. Social Science \& Medicine, 16337-16344.

Nakajima, R. (2007). Measuring peer effects on youth smoking behaviour. The Review of Economic Studies, 74(3), 897-935.

Nakamura, R., Suhrcke, M., \& Zizzo, D. J. (2017). A triple test for behavioral economics models and public health policy. Theory and Decision, 83(4), 513-533.

Nawaz, H., \& Katz, D.L. (2001). American College of Preventive Medicine Practice Policy statement. Weight management counseling of overweight adults. American Journal of Preventive Medicine, 21(1), 73-78. 
Nie, P., Sousa-Poza, A., \& He, X. (2015). Peer Effects on Childhood and Adolescent Obesity in China. China Economic Review, 35, 47-69.

Norton, E.C., Lindrooth, R.C., \& Ennett, S.T. (2003). How measures of perception from survey data lead to inconsistent regression results: evidence from adolescent and peer substance use. Health Economics, 12(2), 139-148.

Pachucki, M.C., Ozer, E.J., Barrat, A., \& Cattuto, C. (2015). Mental Health and Social Networks in Early Adolescence: A Dynamic Study of Objectively-Measured Social Interaction Behaviors. Social Science \& Medicine, 125, 40-50.

Patrick, D.L., Cheadle, A., Thompson, D.C., Diehr, P., Koepsell, T., \& Kinne, S. (1994). The validity of self-reported smoking: a review and meta-analysis. American Journal of Public Health, 84(7), 1086-1093.

Pliner, P., \& Mann, N. (2004). Influence of social norms and palatability on amount consumed and food choice. Appetite, 42(2), 227-237.

Plumridge, E.W., Fitzgerald, L.J., \& Abel, G.M. (2002). Performing coolness: Smoking refusal and adolescent identities. Health Education Research, 17, 167-179.

Polich, J.M. (1982). The validity of self-reports in alcoholism research. Addictive Behaviors, 7(2), 123-132.

Powell, L.M., Tauras, J.A., \& Ross, H. (2005). The importance of peer effects, cigarette prices and tobacco control policies for youth smoking behavior. Journal of Health Economics, 24(5), 950-968.

Prinstein, M.J., \& Cillessen, A.H.N. (2003). Forms and functions of adolescent peer aggression associated with high levels of peer status. Merrill-Palmer Quarterly, 49, 310-342.

Prinstein, M.J., Meade, C.S., \& Cohen, G.L. (2003). Adolescent oral sex, peer popularity, and perceptions of best friends' sexual behavior. Journal of Pediatric Psychology, 28, 243-249.

Rebagliato, M. (2002). Validation of self-reported smoking. Editorial, Journal of Epidemiology and Community Health, 56(3), 163-164.

Reid, J. L., Manske, S. R., \& Leatherdale, S. T. (2008). Factors related to adolescents' estimation of peer smoking prevalence. Health Education Research, 23(1), 81-93.

Renna, F., Grafova, I.B., \& Thakur, N. (2008). The effect of friends on adolescent body weight. Economics \& Human Biology, 6(3), 377-387.

Rice, N., \& Sutton M. (1998). Drinking patterns within households: the estimation and interpretation of individual and group variables. Journal of Health Economics, 7(8), 689699.

Richard-Shubik, S. (2015). Peer Effects in Sexual Initiation: Separating Demand and Supply Mechanisms. Quantitative Economics, 6, 663-702.

Robalino, J.D. (2016). Smoking Peer Effects among Adolescents: Are Popular Teens More Influential? IZA Discussion Paper No. 9714, Institute of Labor Economics.

Rodríguez-Planas, N., \& Sanz-de-Galdeano, A. (2016). Social Norms and Teeange Smoking: The Dark Side of Gender Equality. IZA Discussion Paper No. 10134, Institute of Labor Economics. 
Rosenquist, J.N., Fowler, J.H., \& Christakis, N.A. (2011). Social Network Determinants of Depression. Molecular Psychiatry, 16, 273-281.

Sacerdote, B. (2011). Peer Effects in Education: How Might They Work, How Big Are They and How Much Do We Know Thus Far? Handbook of the Economics of Education, 3, 249-277.

Schoeller, D.A. (1995). Limitations in the assessment of dietary energy intake by selfreport. Metabolism, 44(2), 18-22.

Sen, A. (2009). Estimating the impacts of household behavior on youth smoking: evidence from Ontario, Canada. Review of Economics of the Household, 7(2), 189-218.

Shields, M., Connor Gorber, S., Janssen, I., \& Tremblay, M.S. (2011). Obesity estimates for children based on parent-reported versus direct measures. Health Reports, $22,1-12$.

Soetevent, A.R., \& Kooreman, P. (2007). A discrete-choice model with social interactions: with an application to high school teen behavior. Journal of Applied Econometrics, 22(3), 599-624.

Sotoudeh, R., Conley, D., \& Harris, K.M. (2017). The Influence of Peer Genotypes and Behavior on Smoking Outcomes: Evidence from Add Health (Working Paper No. w24113). National Bureau of Economic Research.

Steffian G. (1999): Correction of normative misperceptions: an alcohol abuse prevention program. Journal of Drug Education, 29, 115-38.

Stormshak, E.A., Bierman, K. L., Bruschi, C. J., Dodge, K. A., Coie, J. D., \& Conduct Problems Prevention Research Group. (1999). The relation between behavior problems and peer preference in different classroom contexts. Child Development, 70, 169-182.

Townshend, J. M., \& Duka, T. (2002). Patterns of alcohol drinking in a population of young social drinkers: a comparison of questionnaire and diary measures. Alcohol and Alcoholism, 37(2), 187-192.

Trogdon, J.G., Nonnemaker, J., \& Pais, J. (2008). Peer effects in adolescent overweight. Journal of Health Economics, 27(5), 1388-1399.

Ugander, J., Backstrom, L., Marlow, C., \& Kleinberg, J. (2012). Structural Diversity in Social Contagion. Proceedings of the National Academy of Sciences, 109, 5962-5966.

Vartiainen, E., Seppälä, T., Lillsunde, P., \& Puska, P. (2002). Validation of selfreported smoking by serum cotinine measurement in a community-based study. Journal of Epidemiology \& Community Health, 56(3), 167-170.

Wagenknecht, L.E., Burke, G.L., Perkins, L.L., Haley, N.J., \& Friedman, G.D. (1992). Misclassification of smoking status in the CARDIA study: a comparison of self-report with serum cotinine levels. American Journal of Public Health, 82(1), 33-36.

Yakusheva, O., \& Fletcher, J. (2015). Learning from Teen Childbearing Experiences of Close Friends: Evidence Using Miscarriages as a Natural Experiment. The Review of Economic Studies, 97(3), 29-43.

Yakusheva, O., Kapinos, K., \& Weiss, M. (2011). Peer effects and the freshman 15: evidence from a natural experiment. Economics \& Human Biology, 9(2), 119-132. 
Yakusheva, O., Kapinos, K. A., \& Eisenberg, D. (2014). Estimating heterogeneous and hierarchical peer effects on body weight using roommate assignments as a natural experiment. Journal of Human Resources, 49(1), 234-261.

Yang, M., \& Huang, R. (2014). Asymmetric association between exposure to obesity and weight gain among adolescents. Eastern Economic Journal, 40(1), 96-118. 


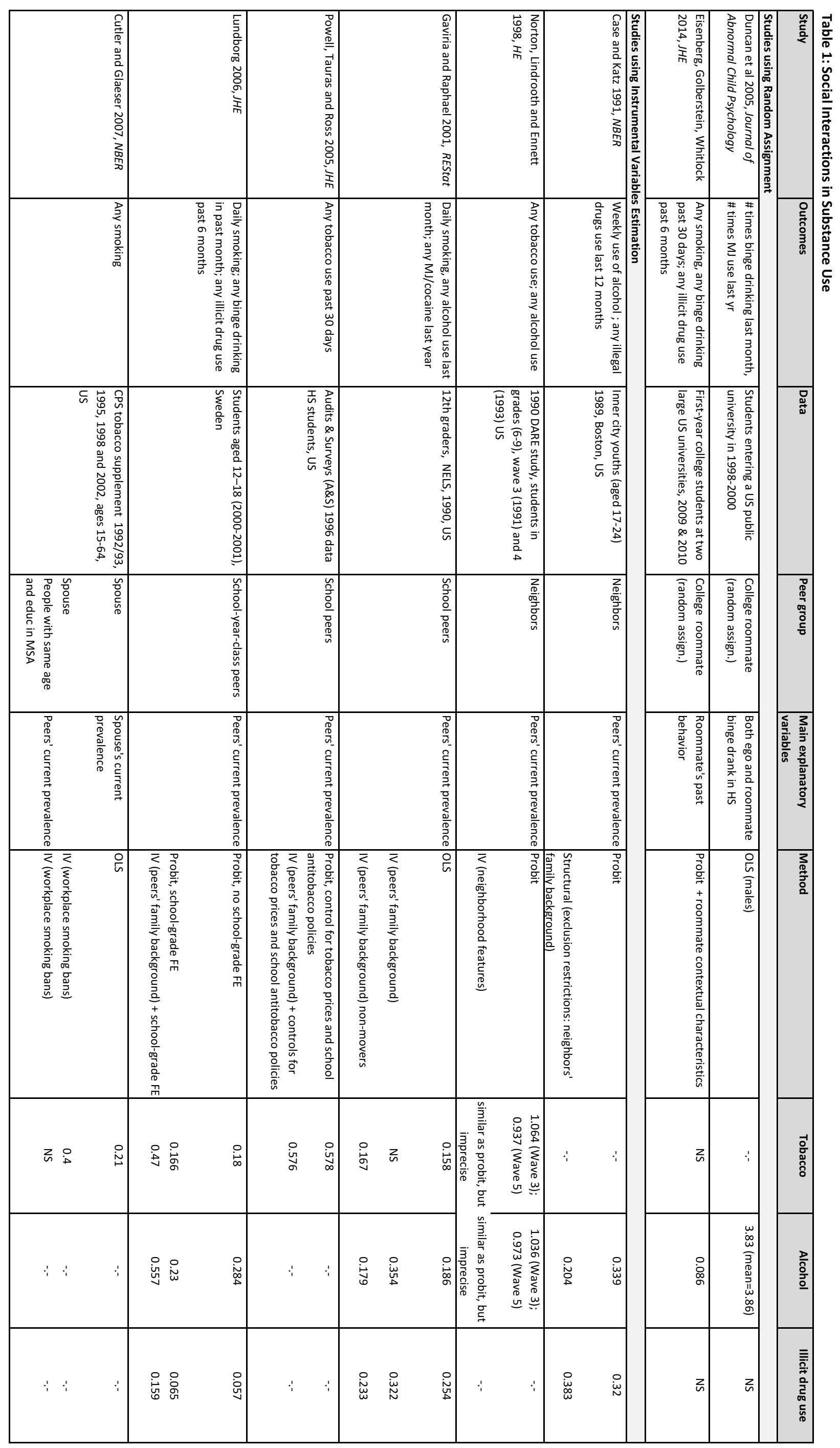




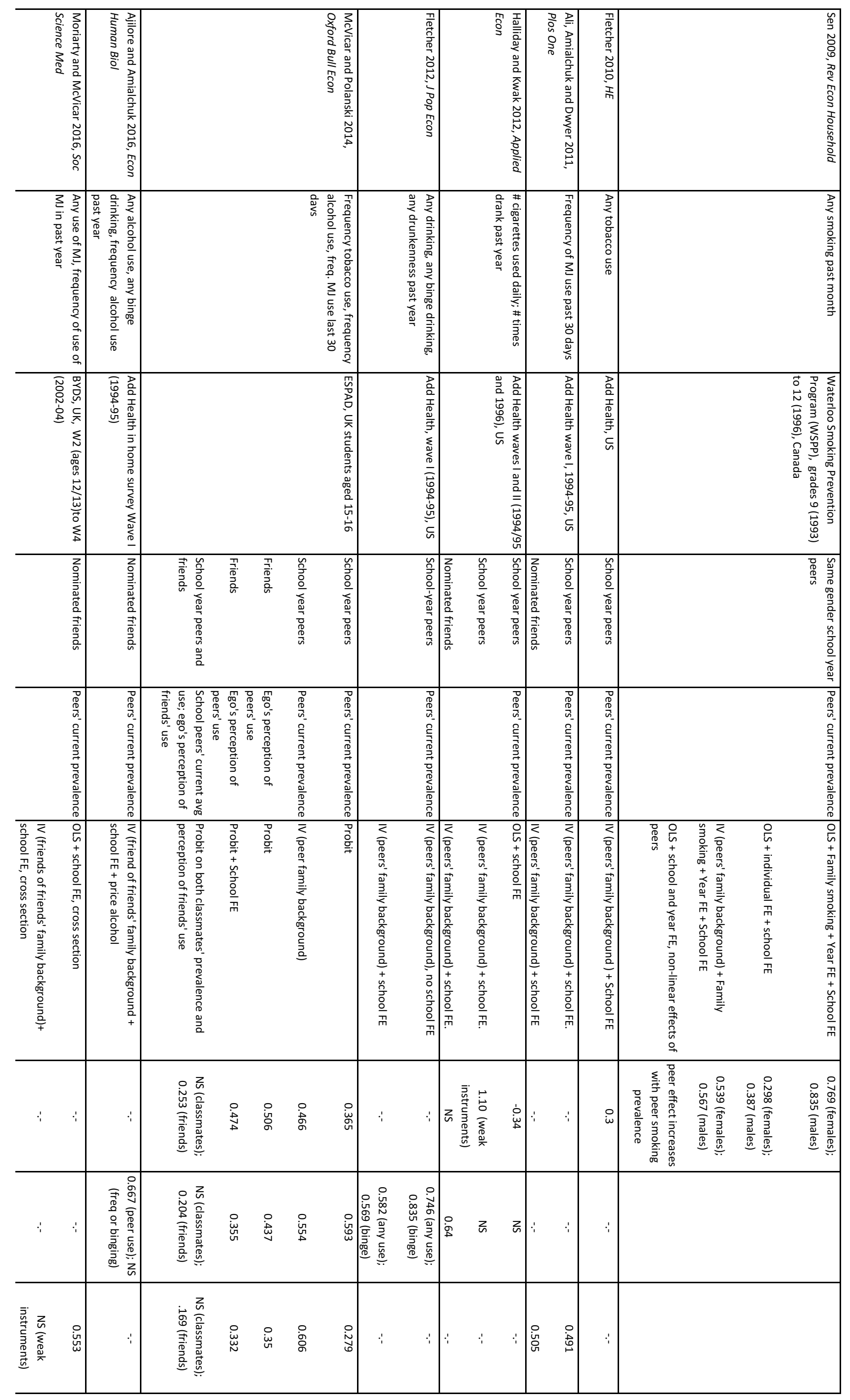




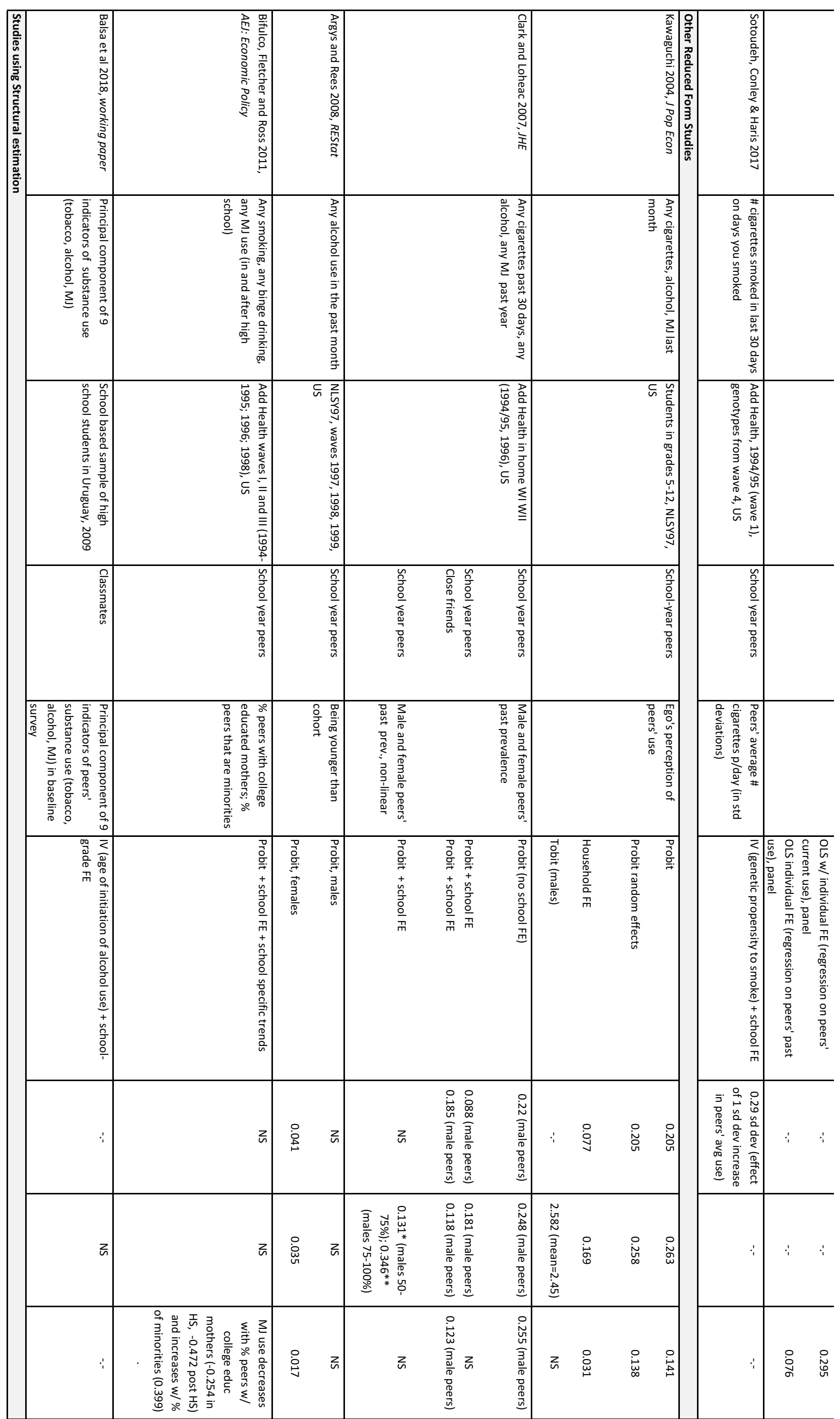




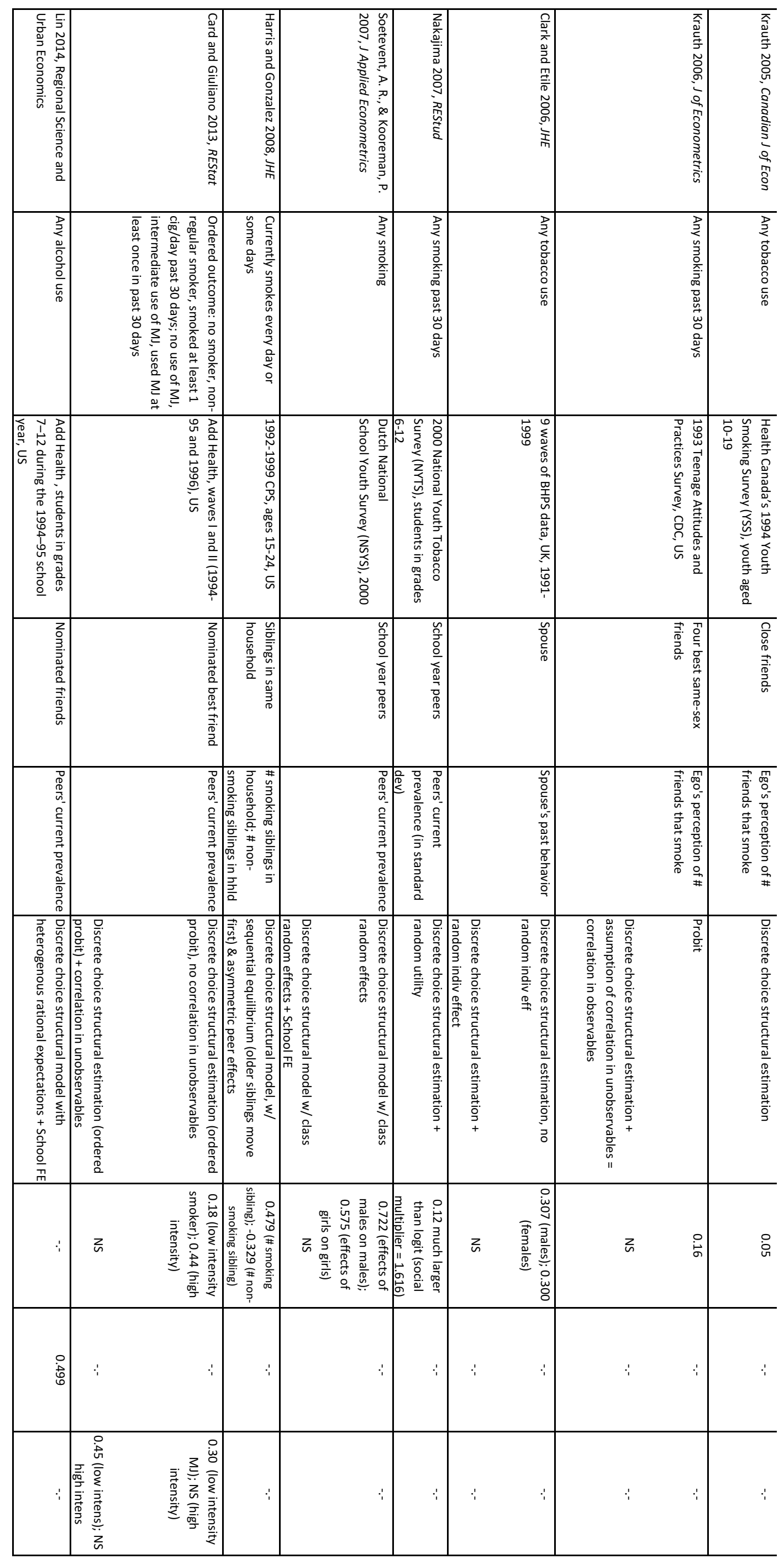




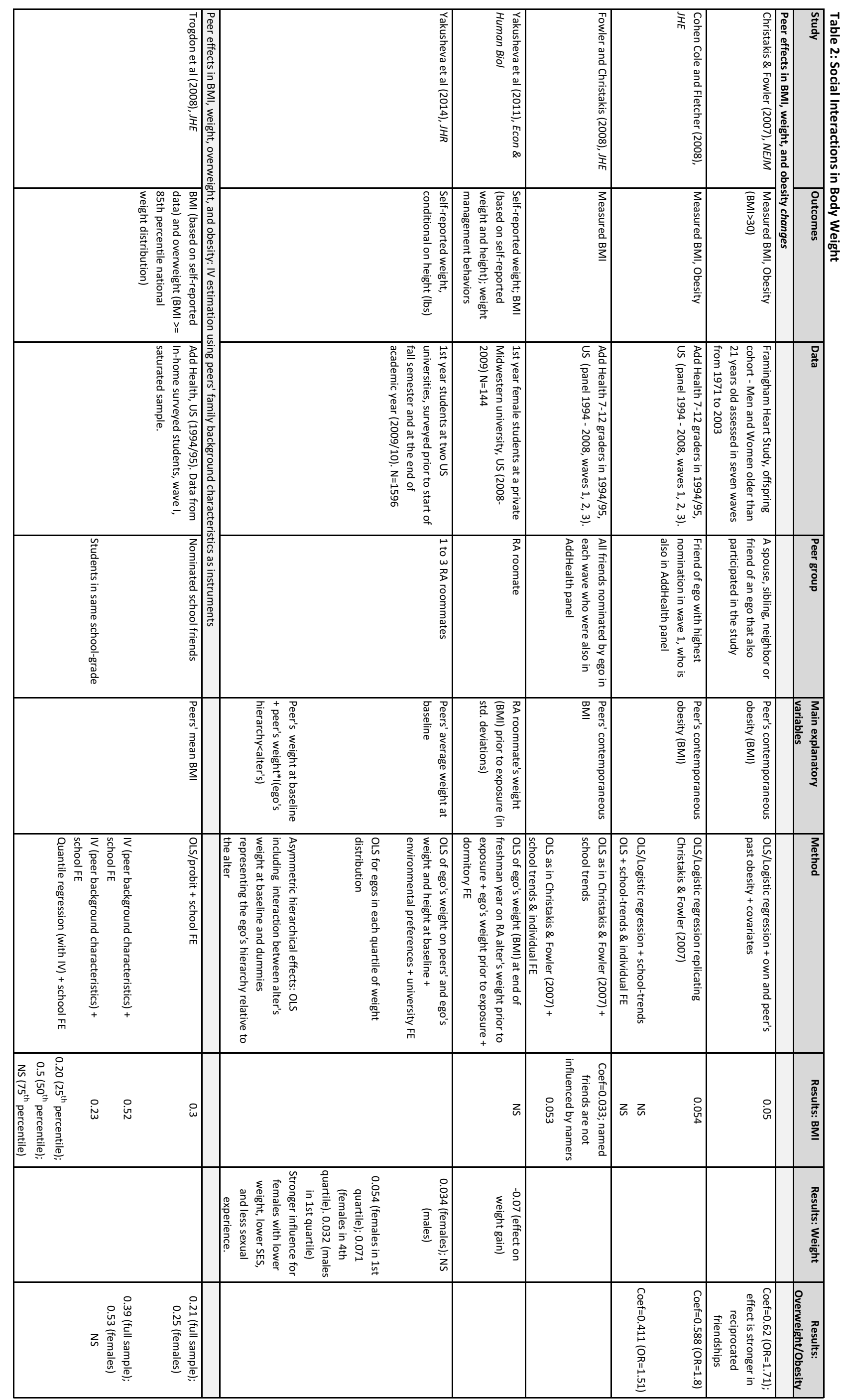




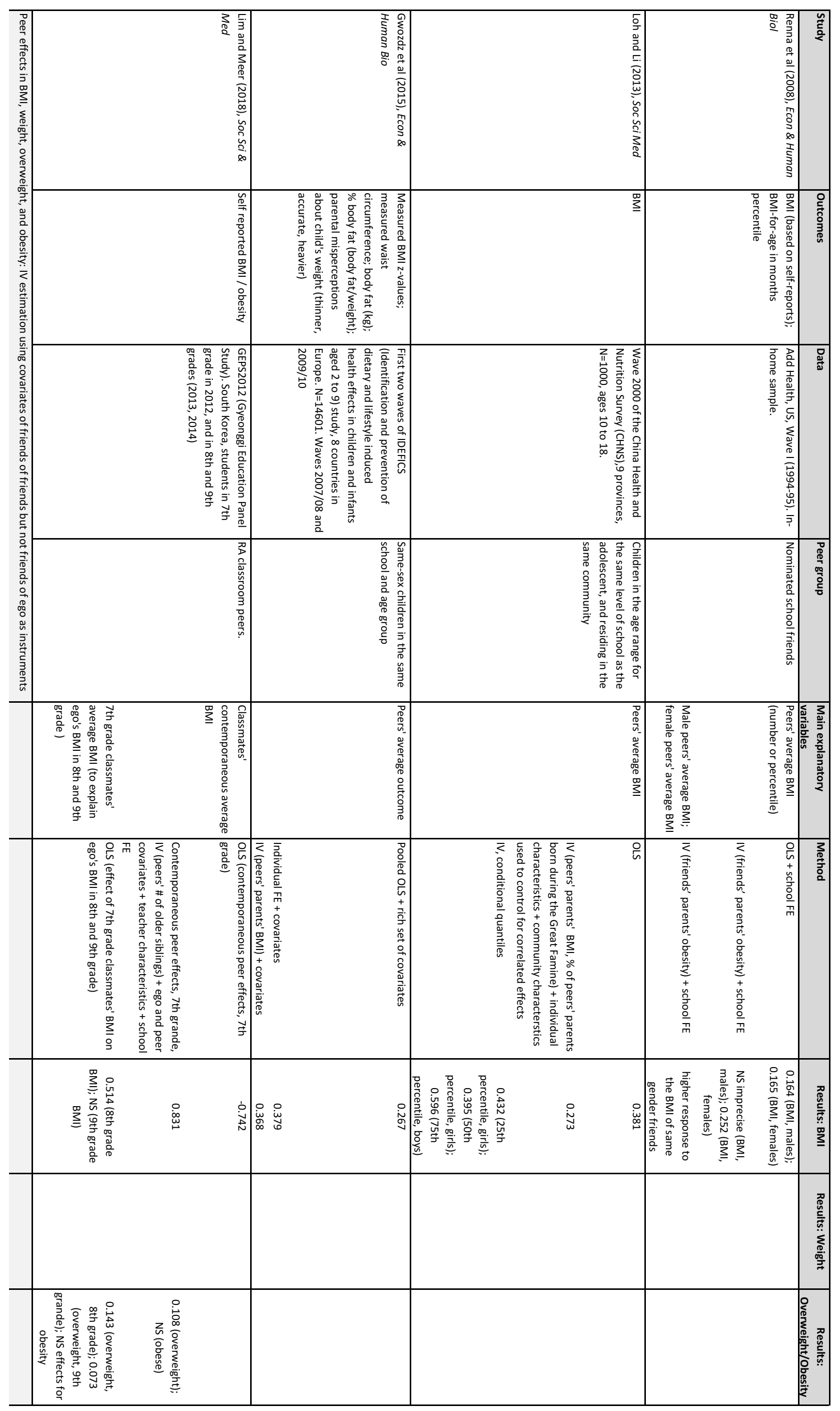




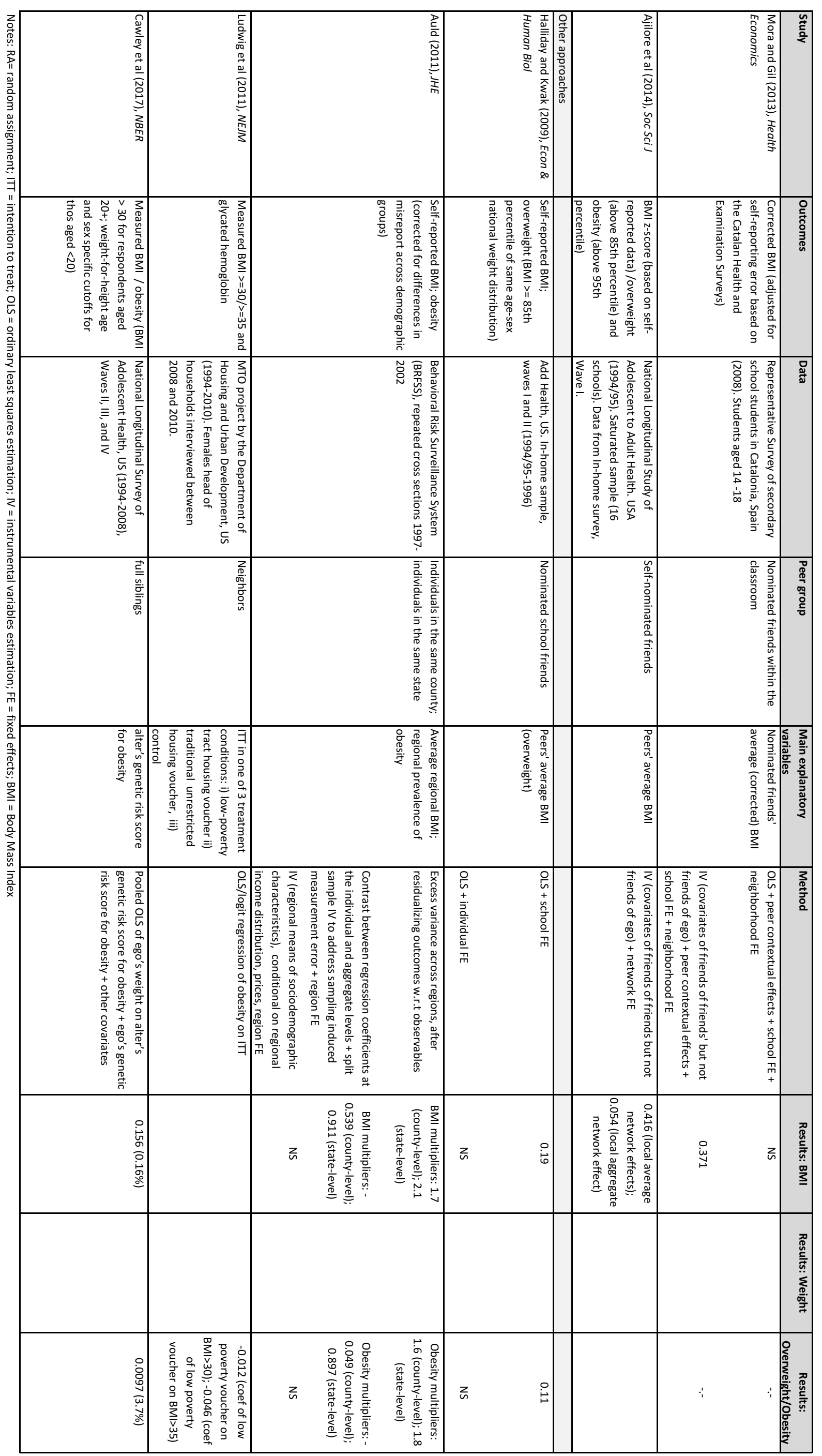




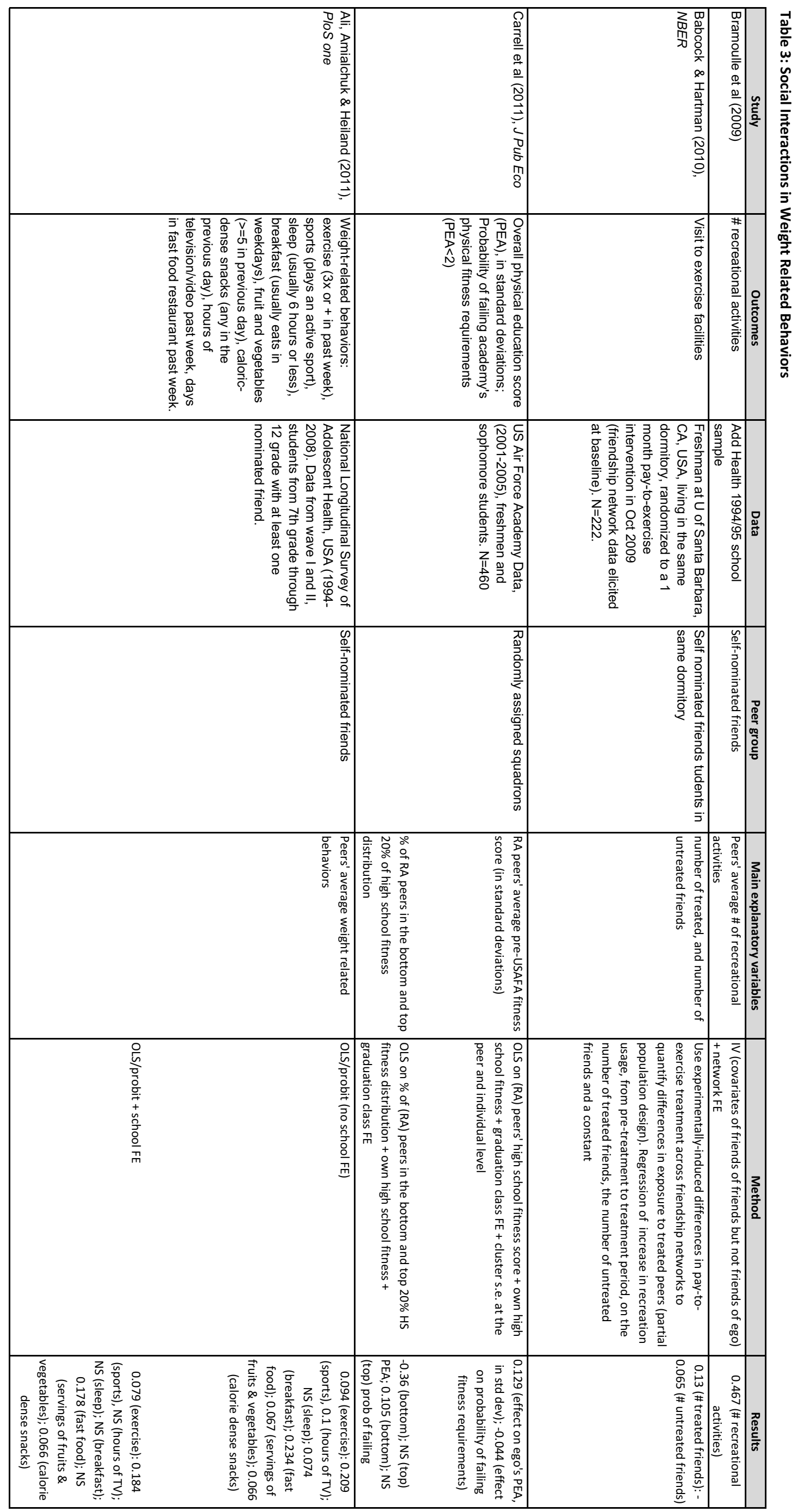




\begin{tabular}{|c|c|c|c|c|}
\hline \multicolumn{2}{|r|}{ 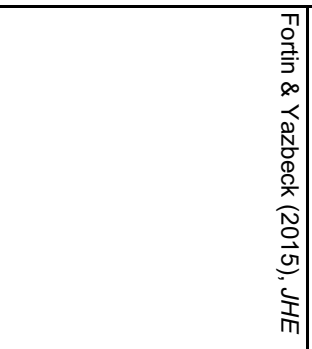 } & 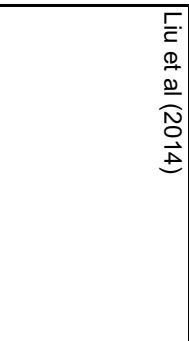 & & 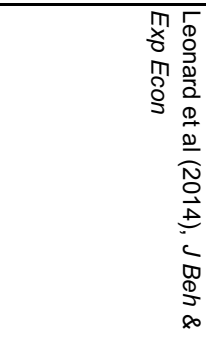 \\
\hline & 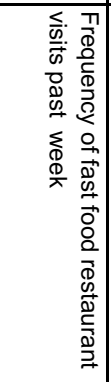 & 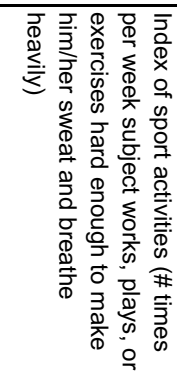 & & 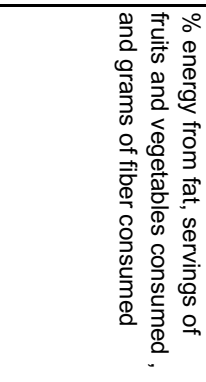 \\
\hline & 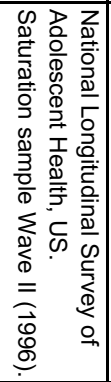 & 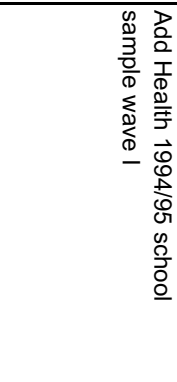 & & 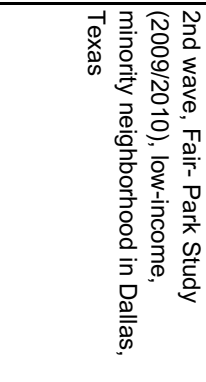 \\
\hline & 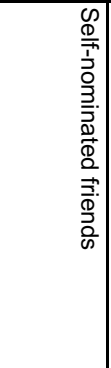 & 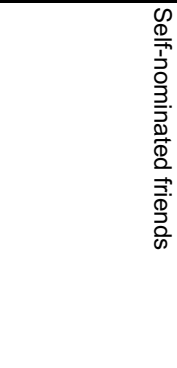 & & 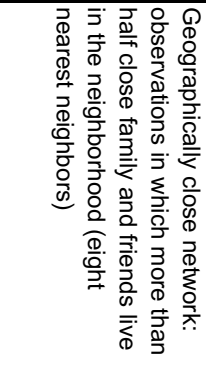 \\
\hline & 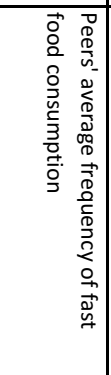 & 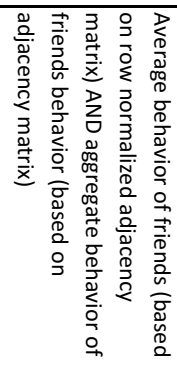 & & 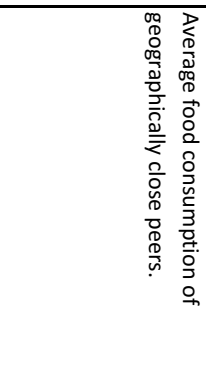 \\
\hline 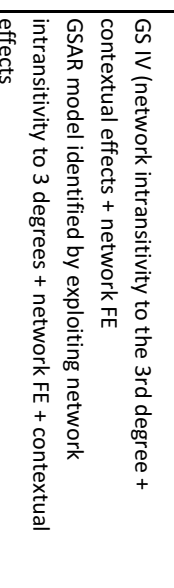 & 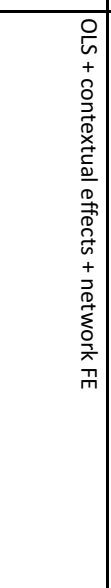 & 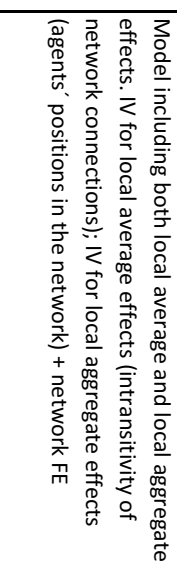 & 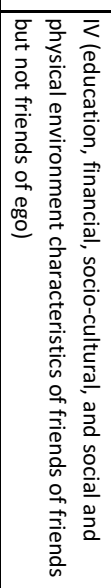 & 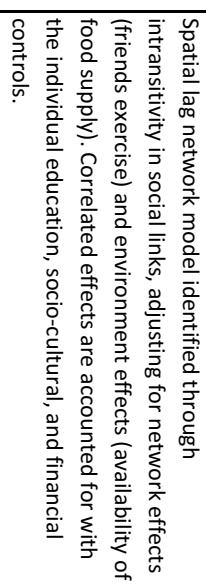 \\
\hline 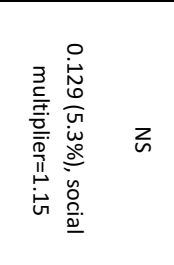 & 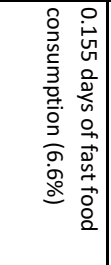 & 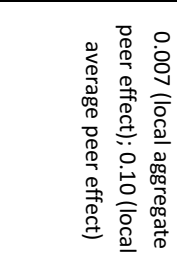 & 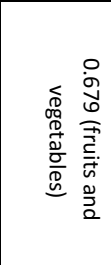 & 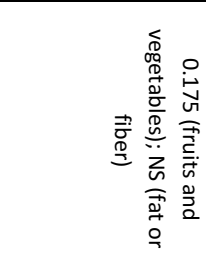 \\
\hline
\end{tabular}




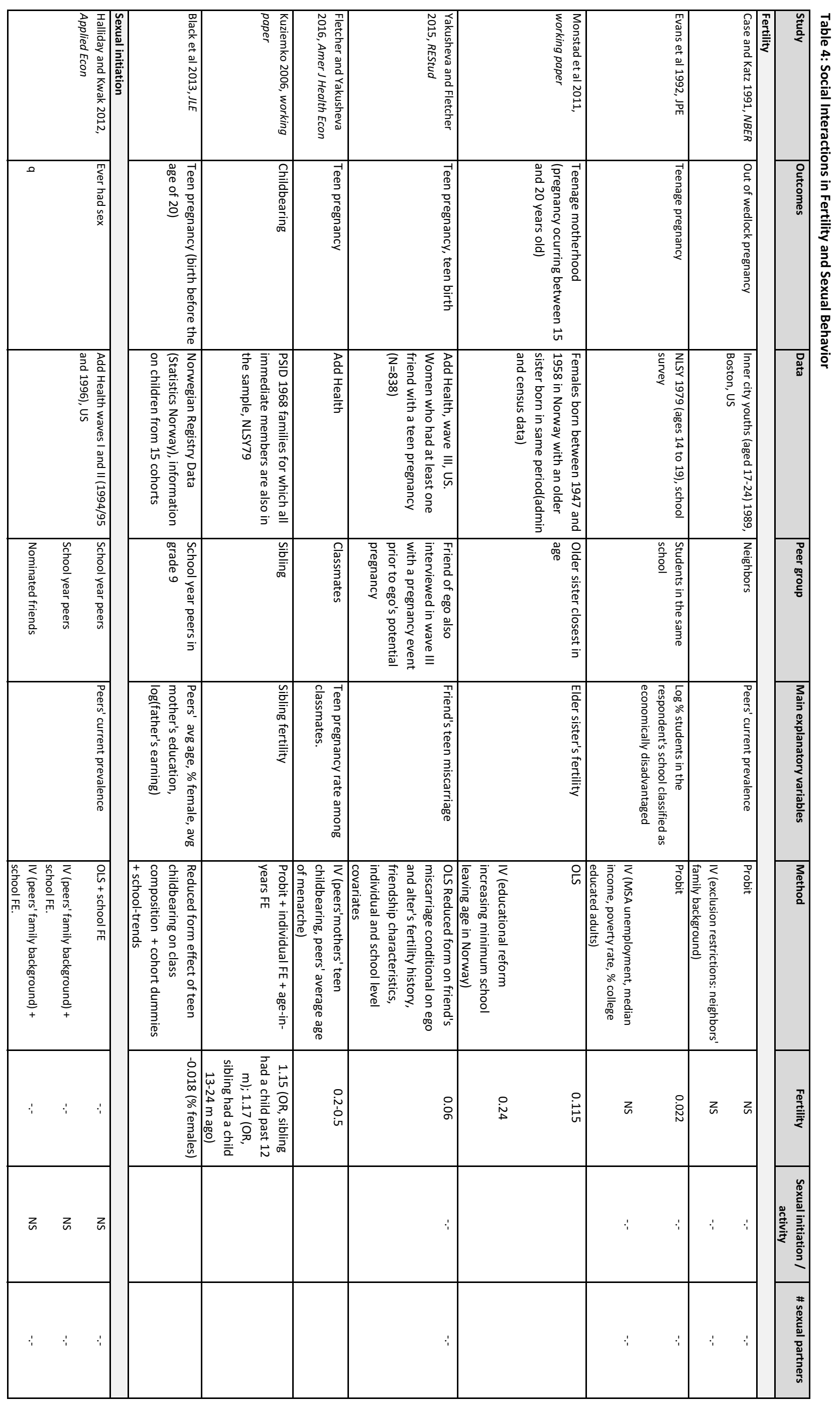




\begin{tabular}{|c|c|c|c|c|c|}
\hline 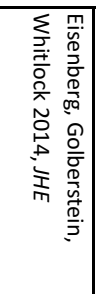 & 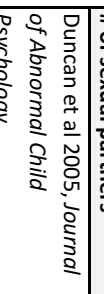 & 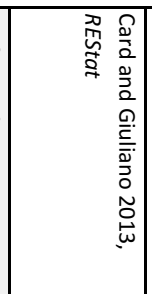 & 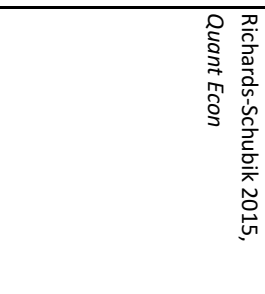 & 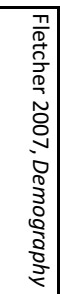 & 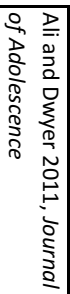 \\
\hline 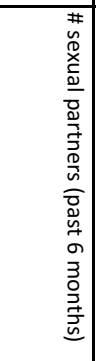 & 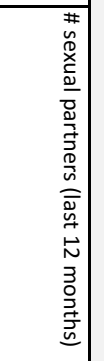 & 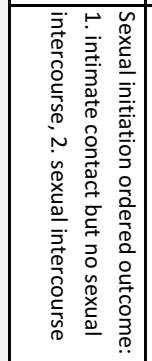 & 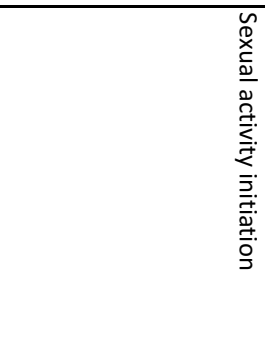 & 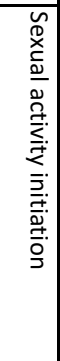 & 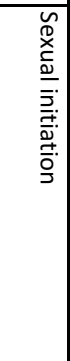 \\
\hline 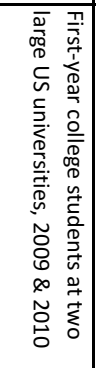 & 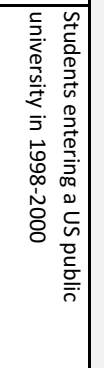 & 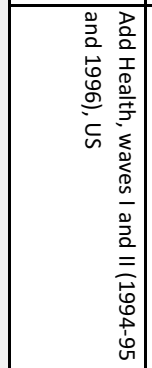 & 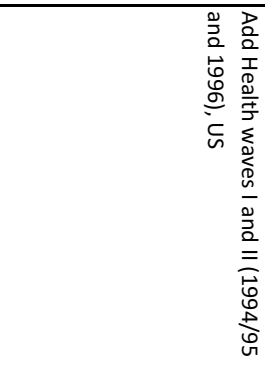 & 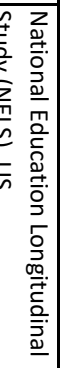 & 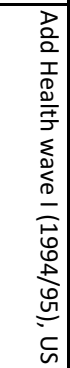 \\
\hline 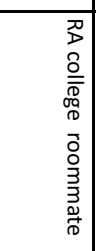 & 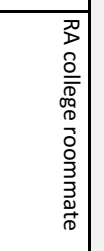 & 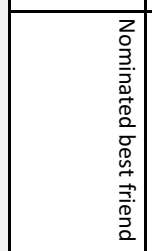 & 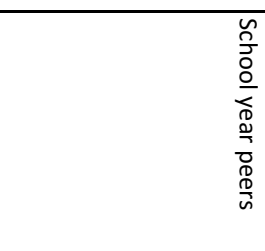 & $\begin{array}{l}0 \\
\frac{\tilde{O}}{0} \\
\frac{0}{\sigma} \\
\frac{0}{0} \\
\frac{0}{\omega}\end{array}$ & 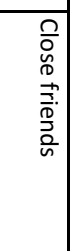 \\
\hline 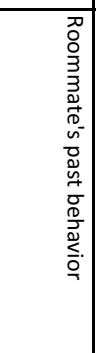 & 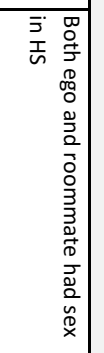 & 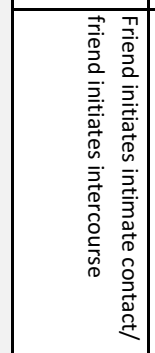 & 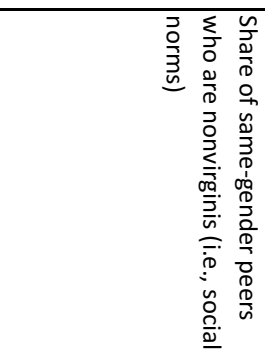 & 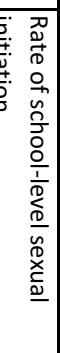 & 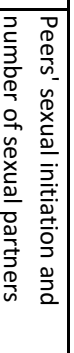 \\
\hline 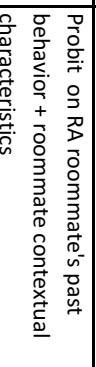 & 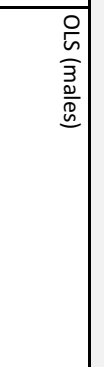 & 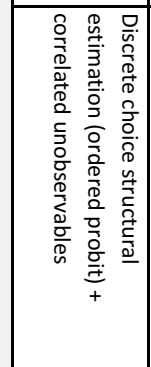 & 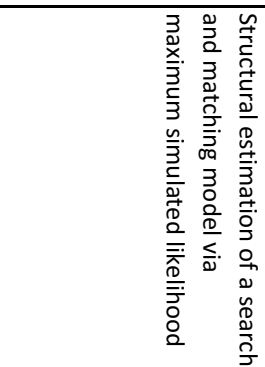 & 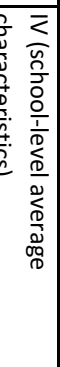 & 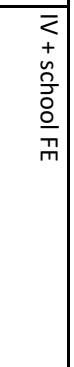 \\
\hline$\therefore$ & $\therefore$ & $\therefore$ & $\therefore$ & $\therefore$ & $\therefore$ \\
\hline & $\therefore$ & 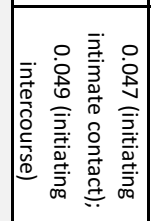 & 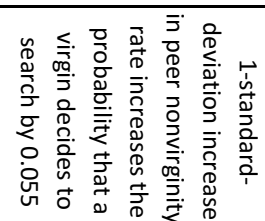 & $\stackrel{o}{\omega}$ & $\stackrel{\circ}{\circ}$ \\
\hline in & $z$ & $\therefore$ & & $\therefore$ & ir \\
\hline
\end{tabular}




\begin{tabular}{|c|c|c|c|c|c|c|c|c|}
\hline 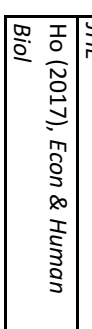 & 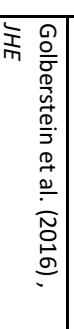 & 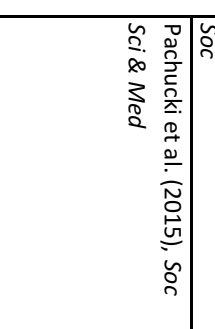 & 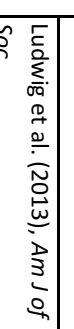 & 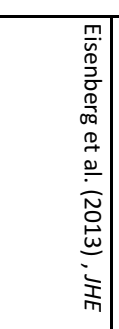 & 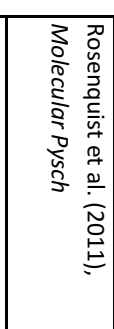 & 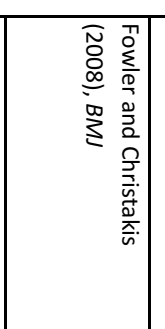 & 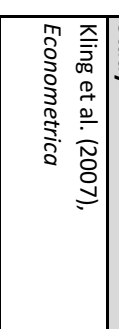 & \\
\hline 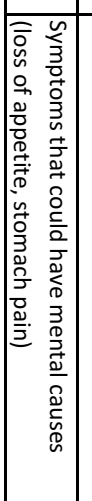 & 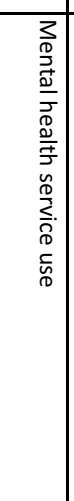 & 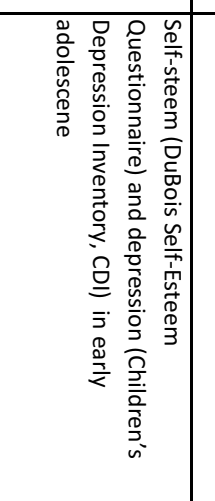 & 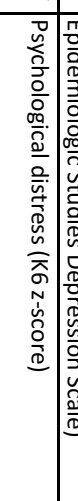 & 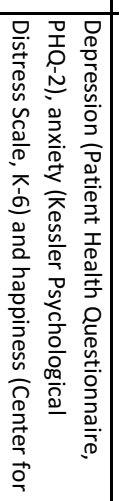 & 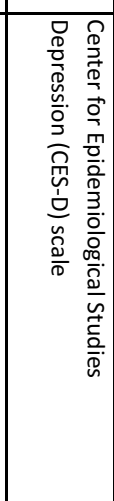 & 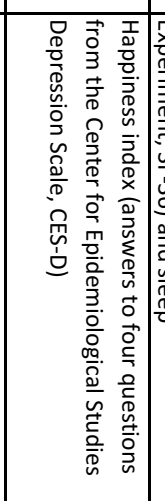 & 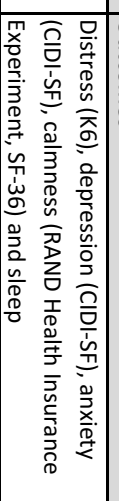 & \\
\hline 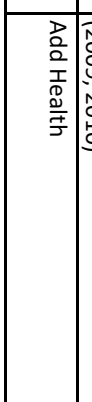 & 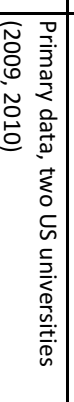 & 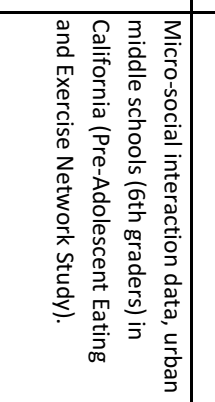 & 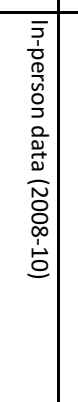 & 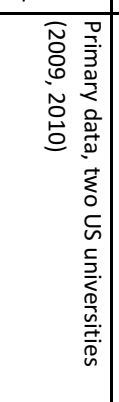 & 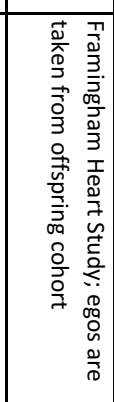 & 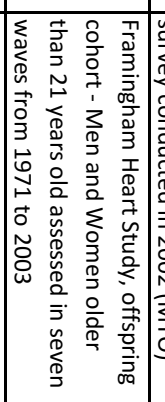 & 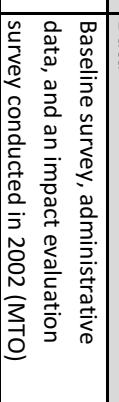 & \\
\hline 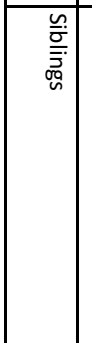 & 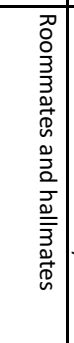 & 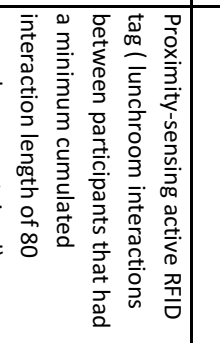 & 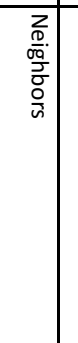 & 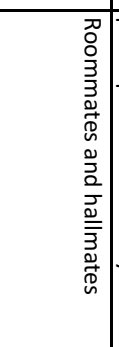 & 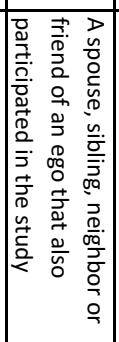 & 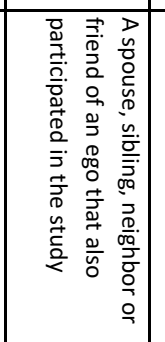 & & 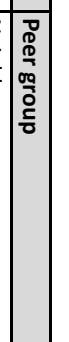 \\
\hline 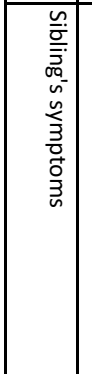 & 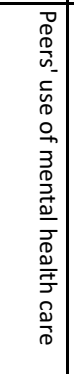 & 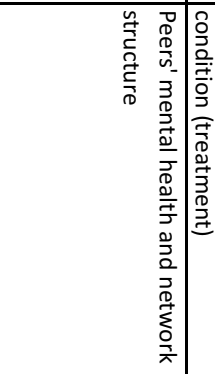 & 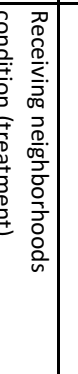 & 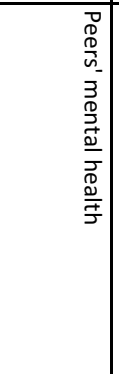 & 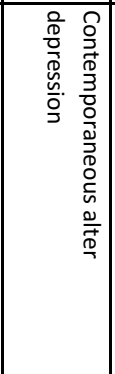 & 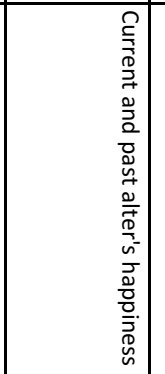 & 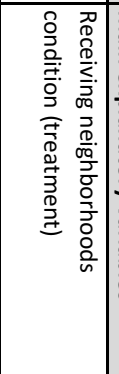 & 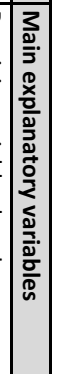 \\
\hline 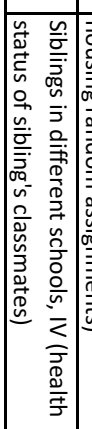 & 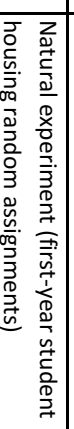 & 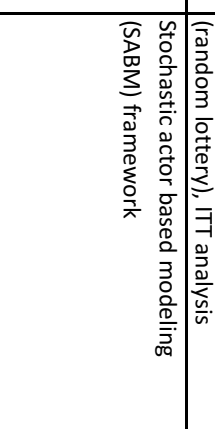 & 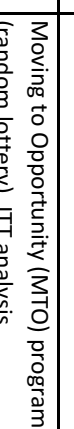 & 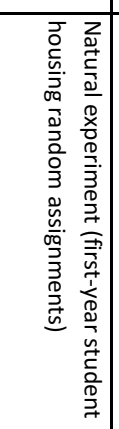 & 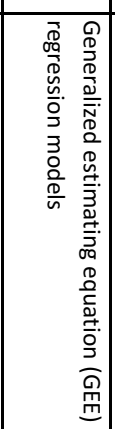 & 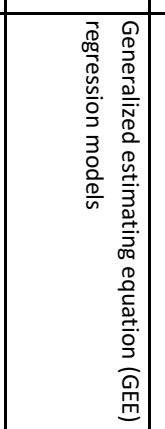 & 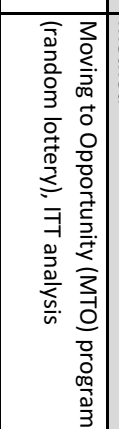 & 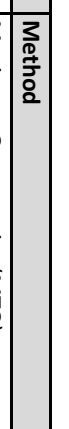 \\
\hline$z_{n}$ & 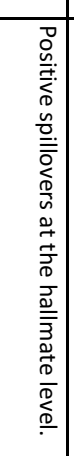 & & 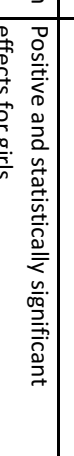 & z & 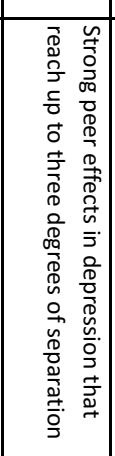 & 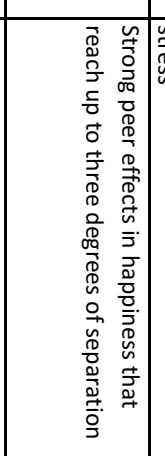 & 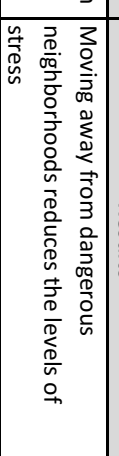 & $\mid$ \\
\hline
\end{tabular}

